\title{
Enhanced Patch-Clamp Technique to Study Antimicrobial Peptides and Viroporins, Inserted in a Cell Plasma Membrane with Fully Inactivated Endogenous Conductances
}

\author{
Marco Aquila ${ }^{1,2,},{ }^{,}$, Mascia Benedusi ${ }^{1,{ }^{*}}$, Alberto Milani ${ }^{1}$ and Giorgio Rispoli ${ }^{1}$ \\ ${ }^{1}$ Dipartimento di Biologia ed Evoluzione, Sezione di Fisiologia e Biofisica, \\ Università di Ferrara, Ferrara \\ 2Institute for Maternal and Child Health - IRCCS "Burlo Garofolo"-Trieste
}

Italy

\section{Introduction}

\subsection{Chapter outline}

Many short peptides (Table 1) selectively permeabilize the bacteria plasma membrane (Fig. 1), leading to their lyses and death: they are therefore a source of antibacterial molecules, and inspiration for novel and more selective drugs. Another class of short $(<100$ residues) membrane proteins called viroporins, because they are coded by viral genes (Table 1), permeabilizes the membrane of susceptible cells during infection of by most animal viruses (Carrasco, 1995; Fig. 1). The permeabilization leads to host cell lyses and the release of the virus mass, replicated at host cell expense, to propagate the infection. Detailed knowledge of the permeabilization properties of these proteins would allow to design, for instance, selective blockers of these pores, that would contrast the spread of the viral infection.

In this chapter, the patch-clamp technique is employed to study the mechanism of membrane permeabilization induced by the pore-forming peptides, under strict physiological conditions. This goal is achieved by recording the ion current through the channels formed by these peptides, once inserted in a cell plasma membrane. To avoid contamination by the cell membrane currents, all the endogenous current sources must be blocked. It has been found that the photoreceptor rod outer segment mechanically isolated from the retina of low vertebrates (OS; Vedovato \& Rispoli, 2007a; Fig. 2) was the most suitable cell to carry on the above studies, because it was possible to fully block all its endogenous currents without using any drug (such as TTX, TEA, dihydropyridines, etc.), that could obstruct the peptide pores or interfere with the pore formation (Fig. 4). The peptides were applied to (and removed from) the extracellular OS side in $~ 50 \mathrm{~ms}$ with a computer-controlled microperfusion system, in which every perfusion parameter (as the rate of solution flow, the temporal sequence of solution changes or the number of automatic,

* These authors contributed equally to this work. 
self-washing cycles) was controlled by a user-friendly interface. This system allowed rapid application and removal of ions, drugs and peptides on the cells with a controlled timing, so that the ion channel characteristics (as its selectivity, blockade and gating) and the dynamics of pore formation could be precisely assessed. On the basis of the electrophysiological recordings obtained with representative peptides and with selected analogs, as alamethicin F50/5 (Crisma et al., 2007; Vedovato \& Rispoli, 2007a; Vedovato et al., 2007; Fig. 5-8), the cecoprine-mellitin hybrid peptide (CM15; Milani et al., 2009; Fig. 5-7), and a 20-amino acids long fragment of the viroporin poliovirus 2B (Madan et al., 2007; Fig. 9), it will be shown that the membrane pore formation occurs according to the barrel and stave, toroidal, and carpet model, respectively (Fig. 1), that are the most widely-accepted mechanisms of membrane permeabilization.

When recording large currents (produced for instance by high concentrations of peptides and/or highly permeable peptides), it is necessary to minimize series resistance, to reduce time constant of charging the cell membrane capacitance and error in membrane potential control. A second problem arises from the asymmetry of the plasma membrane: it is possible that the permeabilization properties of a particular peptide could be different depending upon the side of the membrane to which it is applied. For example, it is conceivable that viroporins are optimized to insert in the intracellular face of the plasma membrane, because they are synthesized in host cell cytosol. These two problems could be circumvented by widening the patch pipette shank, through the calibrated combination of heat and air pressure. These pipettes dramatically reduce series resistance, and allow at the same time to insert pulled quartz or plastic tubes very close to the pipette tip (Benedusi et al., 2011; Goodman et al., 2000; Johnson et al., 2008), making it possible the delivery of large molecules to the cytosol with a controlled timing (Fig. 3). Finally, it is presented here a simple procedure to consistently attain seals with conventional or pressure polished pipettes, made from just one glass type, on a wide variety of cell types, isolated from different amphibian, reptilian, fish, and mammalian tissues, and on artificial membranes made with many different lipid mixtures.

\subsection{Antimicrobial peptides}

The increasing number of common and emerging cases of infection due to antibioticresistant bacteria, occurring for instance in hospitals and in high frequented spaces, requires new and reliable sources of innovative antimicrobials. A promising source of these compounds are the pore-forming peptides, that permeabilize the bacterial membrane up to a point to induce the lyses and death of the pathogen. These peptides are an evolutionarily conserved component of the innate immune response found among all classes of life, and they are one of the oldest form of defense against pathogens. This chapter is focused on two of them: the F50/5 and the CM15 (Table 1). The former peptide is the major component of the neutral fraction of the peptaibol antibiotic alamethicin. The peptaibols (Toniolo et al., 2001) are members of a group of naturally occurring short peptides produced by fungi of the genus Trichoderma, characterized by an N-terminal acyl group, a C-terminal 1,2aminoalcohol and a high content of the non-proteinogenic $\mathrm{C}^{\alpha}$-tetrasubstituted a-amino acid Aib (a-aminoisobutyric acid). Key amino acids of the F50/5 peptide sequence were also modified to understand their implication on the biophysical characteristics of the pore 
(Vedovato et al., 2007). The CM15 is a small 15-residue synthetic hybrid peptide, first described by Andreu et al. (1992), composed of the first seven residues of the silk moth cecropin A and residues 2-9 from the bee venom melittin.

\subsection{Viroporins}

Many RNA viruses encode some 60-120 amino acids integral membrane proteins, called viroporins, which are localized primarily within the endoplasmic reticulum and plasma membrane of host cells. About a dozen proteins that qualify as viroporins have been discovered so far, including poliovirus $2 \mathrm{~B}$, alphavirus $6 \mathrm{~K}, \mathrm{HIV}-1 \mathrm{Vpu}$, hepatitis $\mathrm{C}$ virus (HCV) p7 protein, influenza virus M2, and the coronavirus E (CoVE) protein from the severe acute respiratory syndrome (SARS) virus (Gonzalez \& Carrasco, 2003). Viroporins are not essential for virus replication, but they boost virus growth by taking part in several viral functions, and by perturbing several mechanisms of host cell, as glycoprotein and vesicle turnover, and plasma membrane permeability. The latter occurs because viroporin oligomerization gives rise to hydrophilic pores at the membranes of host cell. These pores are thought to play a crucial role for viral infectivity, possibly by causing the lyses and death of host cell (letting therefore the replicated virus particles to escape the cell), with a mechanism analogous to the bacterial lyses produced by the antimicrobial peptides. This chapter is focused on elucidating the mechanism of membrane permeation produced by the poliovirus 2B (Table 1).

\subsection{Peptides as bioactive molecules and archetypal ion channel}

Besides the development of anti-bacterial and anti-viral drugs, the pore-forming peptides, being the most ancestral form of membrane pores, provide also a simple model system to understand the structure-function relationships of channels and the molecular basis of peptide/protein oligomerization in lipid membranes. Moreover, these peptides are a powerful molecular model on which to build custom molecules with wide-ranging biotechnological application, as ion channel modulators (Hille, 2001), anti-tumorigenic agents (Hoskin \& Ramamoorthy, 2008; Papo \& Shai, 2005), biosensors for many different analytes (which could deliver a configurable binding site for substrates encoded in a readily measured electrical or optical signal; Aili \& Stevens, 2010), and provide a pharmacological approach to cure channelopaties (reviewed in Wilde, 2008). In the latter case, a synthetic channel could be inserted in cells expressing an aberrant ion channel (Wallace et al., 2000) to restore the physiological ion flow. Bacterial and viral peptides may finally provide insights about the evolution of channel selectivity and gating and, more generally, of ion pumps and exchangers. Recent data from many laboratories indicate indeed that secondary transporters are basically pores with an highly specialized gate system, rather than proteins with a transport mechanism completely different from the ion channels one (reviewed in Gadsby, 2009).

\subsection{Mechanism of membrane permeabilization}

Regardless their origin and purpose, all the membrane permeabilizing peptides adhere first parallel to the lipid bilayer (Fig. $1 a$ and $b$ ), they then orient perpendicular to the membrane, and finally they bind together and/or reorganize the lipid bilayer to form transmembrane pores. Because of their amino acid composition, amphipathicity, and cationic charge, three 
distinct mechanisms have been proposed to explain membrane permeabilization: "barrel and stave", "toroidal", and "carpet" (Fig. 1; reviewed in Brogden, 2005).

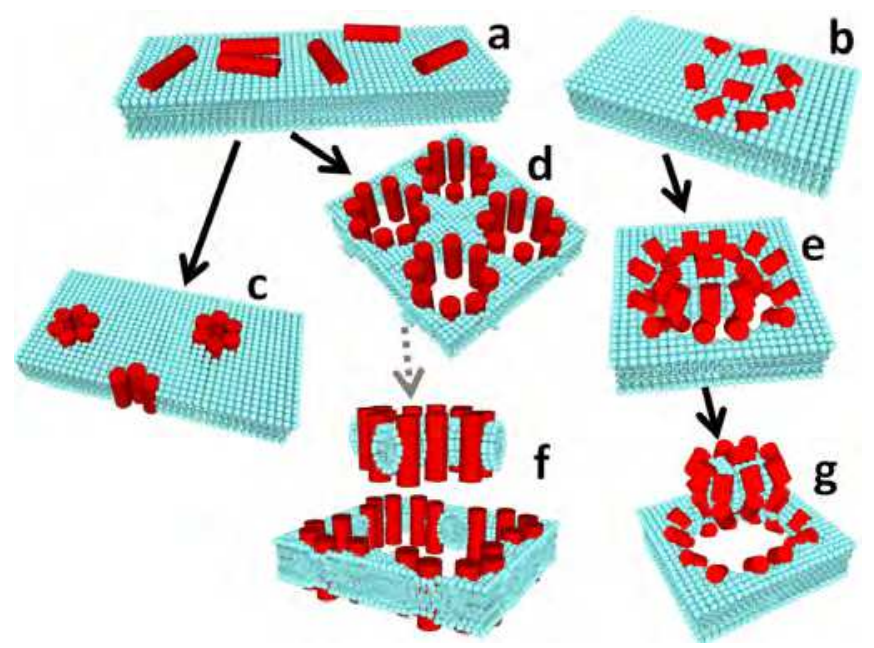

Fig. 1. Mechanisms of permeabilization induced by pore-forming peptides. After adhering on the external face of the membrane $(a$ and $b)$, the peptide could insert in the membrane according to a barrel and stave $(c)$, toroidal $(d$ and $e)$, or carpet mechanism $(f$ and $g$ ).

The first mechanism requires that the peptide monomers, weekly bound to the membrane surface (Fig. 1a), orient perpendicularly to the latter and bind together (as staves) around a central pore (the barrel; Fig. 1c). The peptide hydrophobic segments face the bilayer core, while their hydrophilic segments face the pore lumen. In the toroidal pore, the polar segments of the peptides interact with the polar head groups of the lipids more strongly than in the case of the barrel and stave pore, so that the lipids are forced to tilt from the lamellar normal up to connect the two leaflets of the membrane, forming a continuous bend from one side to the other of the membrane, in the fashion of a toroidal hole (peptides spanning the entire membrane: Fig. $1 d$; peptide shorter than the membrane thickness: Fig. 1e). Differently from the barrel and stave mechanism, the peptides are always associated with the lipid head groups, even when they are perpendicularly inserted in the lipid bilayer. In the carpet mechanism, the strong electrostatic interactions between peptides and the phospholipid head groups result in the peptide carpeting of the membrane (Fig. 1b). The peptides then assemble with the lipids to form transiently toroidal pores (Fig. 1e), allowing more and more peptides to cross the bilayer and eventually cover the other membrane leaflet. Finally, the peptides may isolate a micelle that detaches from the membrane to head to the water phase (Fig. $1 \mathrm{~g}$ ), leading to the bilayer disintegration in a detergent-like manner. It is also possible that the contour of a micelle may be delimited by several toroidal pores that happen to group together (Fig. 1d), and this micelle may eventually separate from the membrane and solubilize (Fig. 1f). Moreover, it is conceivable that the same peptide may permeabilize the membrane with one mechanism or with another (Brogden, 2005), depending upon the surrounding conditions, as the lipid environment, the temperature, the peptide concentration, the presence of some other endogenous or exogenous molecules (Noshiro et al., 2010), etc. 


\section{Methods: Studying peptide-induced permeabilization under strict physiological conditions}

\subsection{Rationale}

Most of the research on the pore-forming peptides has the long-term goal to understand at the molecular level how the peptide-lipid interactions produce structural changes in both, and optimal peptide orientation, to eventually produce a raise in membrane conductance (Chen et al., 2001; Saint et al., 2002). With this aim, a widely used technique consists in recording the ion current flowing through the pore formed by these peptides, inserted in an artificial lipid bilayer. To have an acceptable signal-to-noise ratio in these experiments, it is necessary to apply non-physiological voltages and ionic gradients, that however could affect the peptides themselves, or even the membrane in which they were inserted (Bockmann et al., 2003). Moreover, to our knowledge, no studies aimed to measure the aggregation time course of peptides to form a functioning pore in the plasma membrane of a living cell, and the kinetics of their disaggregation.

In this chapter, the biophysical characteristics and the pore formation dynamics of selected antimicrobial peptides and viroporins, and some of their analogues, were studied under strict physiological conditions. This was accomplished by inserting these (or other) peptide monomers in the plasma membrane of a living cell, and recording the current flowing through the peptide channels at a desired voltage by using the whole-cell, voltage-clamp technique. To make sure that the entire current was flowing through these channels, it was looked for a particular cell system where all the endogenous conductances could be blocked without using any drug, that could affect the peptide pore as well. The outer segment of the photoreceptor rod (OS) mechanically isolated from low vertebrate retinae (Rispoli et al., 1993) is such a cell system, because the only channel type of this cell fragment is fully closed by bright light. The OS of Rana esculenta have been found particularly suitable to carry on this study, because of their large size (Fig. 2a, Inset) and for the commercial availability and low cost of this edible frog species.

To have a precise control of pore formation (and disaggregation), a custom-made, computer controlled microperfusion system was employed to rapidly apply (and remove) the peptides under study onto a cell (Vedovato \& Rispoli, 2007a). Peptide formation and disaggregation dynamics were therefore gathered, respectively, from the time course of the development and fall of the exogenous current (at a given potential, $V_{h}$ ), following peptide application and removal. This system is also capable to apply and remove ions, drugs and peptides on any isolated cell or tissue fragment in $\sim 50 \mathrm{~ms}$ with an accurately controlled timing. This allowed to study in detail the biophysical characteristics of the channels, that are of key importance to assess the peptide performances and its potential biotherapeutic activity.

The pipette tapered shank and the small tip opening give high access resistances $\left(R_{a}\right)$ and constitute the dominant barrier to molecular diffusion between pipette and cell cytosol in the whole-cell recording configuration (Pusch \& Neher, 1988). This shortcoming:

1. gives errors in membrane potential control, due to the voltage drop across the $R_{a}$ in the presence of large membrane currents;

2. impedes the precise measure of current onset and offset kinetics, due to the often too large time constant of charging the cell membrane capacitance through the $R_{a}$; 
3. causes intracellular ion accumulation or depletion, and it slows down the rate of exogenous molecules incorporation via the patch pipette.

It is however possible to enlarge the pipette shank (Goodman et al., 2000; Johnson et al., 2008), through the calibrated combination of heat and air pressure, with a custom made inexpensive set-up (Benedusi et al., 2011). Besides improving the electrical recordings, the enlarged tip geometry of the pressure polished pipettes could accommodate pulled quartz or plastic perfusion tubes close to the pipette tip, allowing the fast and controlled cytosolic incorporation of exogenous molecules.

Another problem of the patch-clamp recording is to gain consistently tight seals: although this technique has been widely used by more than 40 years, little is still known about the nature of the molecular interactions underlying the generation of the seal between membrane and glass (Suchyna et al., 2009). This problem has been addressed here, and it has been found a simple method that allows to consistently attain seals on natural or artificial membranes, by using conventional or pressure polished pipettes made from just one glass type (Benedusi et al., 2011).

\subsection{OS preparation and view}

OS were mechanically isolated from the retina of Rana esculenta in the dark, using infrared illumination and an infrared viewer. Methods are described in detail elsewhere (Vedovato \& Rispoli, 2007a). The retina was "peeled" from an eyecup piece and was gently triturated in Ringer ( $\sim 5 \mathrm{ml})$, using a fire-polished Pasteur pipette to obtain the OS; a Ringer drop containing the OS was then transferred to the recording chamber placed on the microscope (TE 300, Nikon, Tokyo, Japan) stage. The OS were illuminated with an ultrabright infrared LED $(900 \mathrm{~nm})$ and focused on a fast digital camera (C6790-81, Hamamatsu Photonics, Tokyo, Japan) coupled to the microscope. The OS were then viewed in the frame grabber window generated by the AquaCosmos software package (version 2.5.3.0; Hamamatsu Photonics), which controlled all the camera parameters (as gain, frame rate, binning, etc.) as well via a PCI board (PCDIG, Dalsa, Waterloo, ON, Canada).

\subsection{Solutions and electrophysiological recordings}

OS were recorded using the whole-cell configuration of the patch-clamp technique under visual control at room temperature $\left(20-22{ }^{\circ} \mathrm{C}\right.$; Fig. $2 a$, inset $)$. The Ringer solution had the following composition (in $\mathrm{mM}$ ): $115 \mathrm{NaCl}, 3 \mathrm{KCl}, 10$ HEPES free acid [N-(2hydroxyethyl)piperazine- $N^{\prime}$-(2-ethanesulfonic acid)], $0.6 \mathrm{MgCl}_{2}, 0.6 \mathrm{MgSO}_{4}, 1.5 \mathrm{CaCl}_{2}, 10$ glucose (osmolality $260 \mathrm{mOsm} / \mathrm{Kg}$, buffered to $\mathrm{pH}=7.6$ with $\mathrm{NaOH}$ ). All chemicals were purchased from Sigma (St. Louis, MO, USA).

The current amplitude (recorded employing an Axopatch 200B; Molecular Devices, Sunnyvale, CA, USA) elicited by repetitive $-10 \mathrm{mV}$ pulses was used to measure the seal resistance during cell-attached recording. Once the whole-cell recording configuration was obtained, the current transients produced by these repetitive pulses were used to measure the OS membrane resistance $\left(R_{m}\right)$, the access resistance $\left(R_{a}\right)$, and the membrane capacitance $\left(C_{m}\right)$. Peptides (whose primary sequence are reported in Table 1 ) were applied and removed in $\sim 50 \mathrm{~ms}$ by switching forth and back the OS from a stream of control solution [composition (in $\mathrm{mM}$ ): $130 \mathrm{KCl}, 1 \mathrm{CaCl}_{2}$ and $10 \mathrm{HEPES}$; osmolality $260 \mathrm{mOsm} / \mathrm{Kg}$, buffered to $\mathrm{pH}=7.6$ 
with $\mathrm{KOH}$ ] to a stream of control solution containing the peptide under test (see paragraph 2.5). Patch pipettes were filled with control solution as well in order to drive the current just with the holding potential $\left(V_{h}\right.$, that was typically $\left.-20 \mathrm{mV}\right)$.

The stability of the recording was checked by routinely measuring $R_{m}, R_{a}$, and $C_{m}$ in control perfusion solution, i.e. before and after each peptide application. Recordings were filtered at $2 \mathrm{kHz}$ via an eight-pole Butterworth filter (VBF/ $8 \mathrm{Kemo}$, Beckenham, UK), sampled on-line at $5 \mathrm{kHz}$ by a Digidata 1322A (Molecular Devices) connected to the SCSI port of a Pentium computer running the pClamp 9.0 software package (Molecular Devices), and stored on disk. Data were further low-pass filtered off-line at 200 or $500 \mathrm{~Hz}$ using a Gaussian filter, or by using the "running average" routine of SigmaPlot (version 8.0; Jandel Scientific, San Rafael, CA, USA), and analyzed using Clampfit (version 9.0; Molecular Devices). Figures and statistics were performed using SigmaPlot; results are given as means \pm SEM.

\subsection{Peptide sequences and usage}

The primary structure of all peptides studied in this chapter is reported in Table 1. CM15 and its scrambled version were dissolved in bi-distilled water, F50/5 and its analogs in methanol, and the peptide fragments of poliovirus 2B in dimethyl sulfoxide (DMSO), to get a $50,100,500$, and $1000 \mu \mathrm{M}$ stock solutions; an aliquot of one of these peptide stocks was dissolved in the perfusion solution to get a final peptide concentration of $0.25,0.33,0.1,1$, 2.5, 5 and $10 \mu \mathrm{M}$, and used within $30 \mathrm{~min}$. Control experiments proved that the methanol and DMSO contamination of the perfusion solution (no larger than $10 \mathrm{nl} / \mathrm{ml}$ and $1 \mu \mathrm{l} / \mathrm{ml}$, respectively) did not cause any non-specific membrane permeabilization.

\begin{tabular}{|l|l|}
\hline \multicolumn{1}{|c|}{ Peptide } & \multicolumn{1}{c|}{ Sequence } \\
\hline F50/5 & Ac-UPUAUAQUVUGLUPVUUQQ-Phol \\
\hline$\left[L-G l u(O M e)^{18,19]}\right]$ & Ac-UPUAUAQUVUGLUPVUUEE-Phol \\
\hline$\left[L-G l u(O M e)^{7,18,19]}\right]$ & Ac-UPUAUAEUVUGLUPVUUEE-Phol \\
\hline CM15 & Ac-KWKLFKKIGAVLKVL-NH ${ }_{2}$ \\
\hline Scrambled CM15 & Ac-KWKLKFKIGLVKLVAV-NH 2 \\
\hline Poliovirus 2B & $\begin{array}{l}\text { GITNYIESLGAAFGSGFTQQISDKITELTNMVTSTITEKLLKNLI } \\
\text { KIISSLVIITRNYEDTTTVLATLALLGCDASPWQWLRKKACDV } \\
\text { LEIPYVIKQ }\end{array}$ \\
\hline
\end{tabular}

Table 1. Residue sequences of the peptides studied here. Ac, acetyl; Phol, phenylalaninol.

CM15 and its scrambled version were a generous gift of Dr. Feix of Department of Biophysics, Medical College of Wisconsin, Milwaukee, WI, USA; F50/5 and its analogs were synthesized in the lab of Dr. Toniolo of Department of Chemistry of the University of Padua, Italy (Peggion et al., 2004); the peptide fragments of poliovirus 2B were synthesized in the lab of Dr. Nieva of Unidad de Biofísica (CSIC-UPV/EHU), Universidad del País Vasco, Bilbao, Spain (Madan et al., 2007).

\subsection{Fast perfusion system}

After obtaining the whole-cell recording, the OS was aligned in front of a multibarreled perfusion pipette of a fast microperfusion system (Fig. $2 a$ ). The perfusion pipette was moved on a horizontal plane with a precision step motor, controlled by a user-friendly interface 


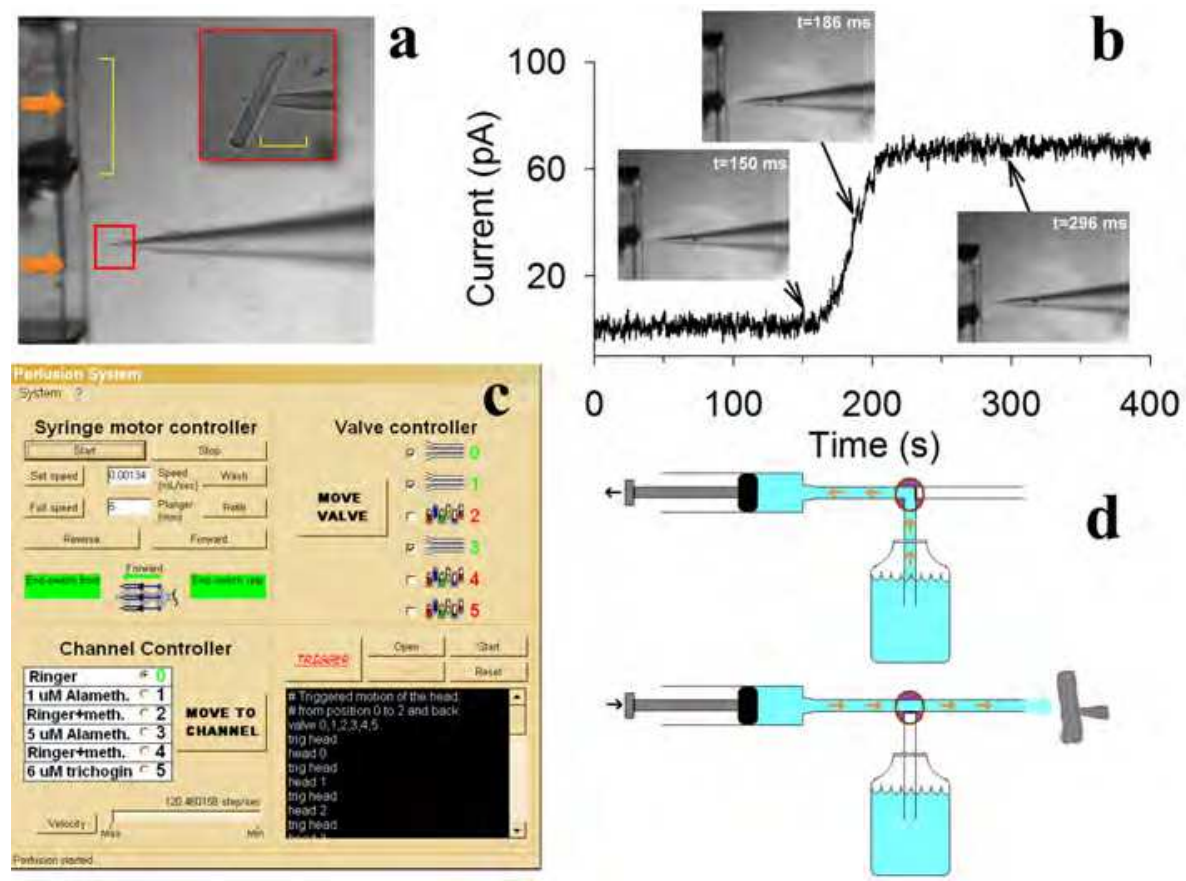

Fig. 2. The technique employed to investigate the permeabilization properties of the peptides inserted in a natural membrane. $a$, a whole-cell recorded OS (shown enlarged in the inset; scale bar is $20 \mu \mathrm{m}$ ) aligned in front of the perfusion pipette (scale bar is $500 \mu \mathrm{m}$; horizontal orange arrows denote perfusion flows). $b$, trace shows the current jump upon switching an open patch pipette filled with $130 \mathrm{mM} \mathrm{K}++1 \mathrm{mM} \mathrm{Ca}^{2+}\left(9 \mathrm{M} \Omega, V_{h}=0 \mathrm{mV}\right)$ from $65 \mathrm{mM}$ choline $+65 \mathrm{mM} \mathrm{K}^{+}+1 \mathrm{mM} \mathrm{Ca}^{2+}$ to $130 \mathrm{mM} \mathrm{K}^{++1} \mathrm{mM} \mathrm{Ca}^{2+}$. The two latter solutions had a $0.6 \mathrm{mV}$ junction potential, producing a current jump of $70 \mathrm{pA}$, lasting $\sim 50 \mathrm{~ms}$, that had the same kinetics of the solution change. This kinetics is also shown by the three still frames (650x494 pixels at 12 bits grey-scale resolution), extracted from a 30 frame/s movie synchronized with the voltage-clamp recording. The boundary separating the two solution streams was clearly visible, allowing a precise electrical and visual correlation of the solution change dynamics. $c$, user interface of the perfusion apparatus. $d$, scheme of one perfusion line (composed by a syringe, a three-way valve, a cylinder and one perfusion pipette barrel) and perfusion flow (in orange) during syringe refilling (upper panel) and during perfusion of an OS recorded in whole-cell (lower panel); drawing not in scale.

(Fig. 2c) running in a host computer, connected to the microperfusion system via the serial port. The perfusion pipette was constituted of up to six barrels $(500 \mu \mathrm{m}$ of side; two barrels of a four barrelled pipette are visible in Fig. 2a) made with precision, square glass capillaries glued together. Peptides were applied and removed in $\sim 50 \mathrm{~ms}$ (see below) by moving the perfusion pipette so that to switch the whole-cell recorded OS back and forth from a stream of control perfusion solution (usually containing $130 \mathrm{mM}$ of a monovalent cation and $1 \mathrm{mM}$ $\mathrm{Ca}^{2+}$; see Results) to a stream containing the peptide (dissolved in the same perfusion solution). This strategy allowed to assess the dynamics of the pore formation and the 
possible reversibility of the process. The temporal lag between the time in which the command (internal or triggered by an external device) moving the perfusion pipette was imparted, and the time in which the solution change effectively occurred, as well as the speed of the solution change, were occasionally measured (since they were very reproducible) as illustrated in Fig. $2 b$. At the end of experiment, the cell was blown off the patch pipette with a positive pressure pulse, and the odd perfusion lines were filled with a solution having $50 \%$ choline chloride and $50 \% \mathrm{KCl}$, while the even perfusion lines were filled with the patch pipette solution. The choline chloride had a different refraction index in respect to all the patch pipette solutions used, therefore the boundary separating two adjacent streams was clearly visible (see the three still frames of Fig. $2 b$ ). Since a junction potential was also developed between the two solutions, upon repeating the solution changes previously performed with the OS, a current jump was recorded by the open pipette (voltage-clamped at $0 \mathrm{mV}$ ) that had the same kinetics of the solution change (Fig. $2 b$ ). By comparing the electrical and the imaging recordings, it results that the solution change was completed within the $50 \mathrm{~ms}$ necessary to the OS to cross the boundary separating two adjacent streams.

The perfusion system could be also used to apply solutions to the cell of different ionic composition or containing a specific drug, so that to study, besides the current-to-voltage characteristics, the ion selectivity and blockade of the pore as well. To this aim, all perfusion solutions contained the peptide under study at the same concentration, so that to compare the effects of the test solutions at a constant membrane permeabilization.

The solutions flowing in the perfusion pipette were fed by means of precision syringes (Hamilton, Reno, NV, USA), whose piston was moved by a DC motor controlled via the computer interface (Syringe motor controller panel, Fig. 2c). The typical perfusion speed was $15 \mu \mathrm{l} / \mathrm{min}$, therefore minimal amounts of peptide solution $(<500 \mu \mathrm{l})$ were required to perform peptide applications lasting more than half an hour. The fine regulation of the perfusion flow speed and of the velocity of perfusion pipette horizontal movements (controlled by the Velocity button in the Channel Controller panel) allowed to perform fast solution changes on practically any isolated cell type, or even on small cell aggregates, without any significant change of the seal resistance. This system has been successfully tested on cells mechanically or enzymatically isolated from different amphibian, reptilian, fish, and mammalian tissues, on cultured cells and on giant unilamellar vesicles made with many different lipid mixtures. Depending upon the position of the six three-way solenoid valves (Fig. 2d; all tubing and valve components in contact with the solutions were made in teflon), each one independently controlled by the Valve controller panel (Fig. 2c), the solution contained in each syringe could be sent to the perfusion pipette (symbolized by the perfusion pipette in the Valve controller panel; Fig. 2c) or redirected to one of the six reservoirs (in which each solution was made, symbolized by a group of cylinders in the Valve controller panel). This allowed to save the solutions that were not used, or to avoid that, upon switching between two non-adjacent barrels, the OS was transiently exposed to a third undesired solution. Once emptied, the syringes could be refilled from the cylinders by clicking on the Refill button (in the Syringe motor controller panel, Fig. $2 c$ ). This command moved the six three-way valves in the cylinder position and backed up the DC motor at full speed until the syringes were filled: the motor was then stopped by an end-position switch; a second end-position switch stopped the motor when syringes were emptied (the status of 
the switches was signaled by the End switch rear and the End switch front indicators in the Syringe motor controller panel, that turned from green to red). When particularly precious solutions were used, all the perfusion lines were filled with control solution and the connectors to the perfusion pipette were detached and immersed in the vials containing the precious solutions. The syringe motor was then backed up and these solutions filled just the terminal portion of the tube between the valve and the perfusion pipette. The connectors were replaced and the motor was started in the forward direction for just enough time to fill the pipette barrels; at this point the perfusion pipette was brought in the recording chamber and the experiment was initiated. At the end of the experiment, all the perfusion lines could be washed by dipping all the tubes previously dipped in the cylinders (or in the vials), into a container filled with distilled water (or other washing solution, as methanol, ethanol, DMSO, etc.), and clicking the Wash button in the Syringe motor controller panel. This command activated the valves and moved the motor back and forth at full speed, so that the syringes were emptied through the perfusion pipette and refilled with the wash solution, a number of times set by the user in a sub-window opened by the Wash button (not shown). The timing and sequence of the solution changes (i.e. the direction, speed and travel of the perfusion pipette step motor), the syringe motor speed, start, stop and direction, and each valve position could be also automatically controlled by simple instructions, entered as a text code (visible in white characters in the black window of Fig. 2c). A set of instructions of arbitrary length could be manually executed in sequence by clicking on the TRIGGER button; each instruction could be executed after an arbitrary delay set by a particular instruction, that would therefore set the sequence timing. Every instruction could be also executed after receiving a trigger pulse from an external device, allowing, for example, the synchronization of the solution changes with the pClamp voltage protocols (as in the experiments shown in Fig. 5-9) or with an imaging system (as in the experiments of Fig. 2b). It was also possible to send out a trigger pulse, after executing a set of instruction of arbitrary length, to synchronize other external devices.

\subsection{Pressure polish pipette}

Patch pipettes were pulled in the conventional manner from 50 or $100 \mu$ l borosilicate glass microcaps (Drummond, Broomall, PA, USA), with a vertical puller (model PP-830, Narishige, Tokyo, Japan), and tightened into a pipette holder. The latter was clamped to the microscope stage, and a three-way valve allowed to connect the pipette to a pressurized air line (set to $\sim 4 \mathrm{~atm}$ and filtered to $0.2 \mu \mathrm{m}$ to avoid pipette clogging), or to vent it to air. The pipette holder was moved by means of the $X Y$ manipulator of the microscope stage, to center the pipette tip into the central bend of an "omega" shaped, glass-coated platinum filament (50 $\mu \mathrm{m}$ of diameter; Fig. $3 a$ and $b$ ). This shape ensured the homogeneous softening of the pipette shank, when the filament was heated by passing a constant current through it. To avoid metal evaporation onto the pipette, the filament was uniformly glass-coated by dipping it in borosilicate glass powder when heated to yellow color. The filament was tin soldered to a copper holder (that functioned also as a heat sink, Fig. 3a) mechanically coupled to a micromanipulator, and electrically connected to a variable current generator via a "push-to-make" switch. To produce the adequate heat to soften the pipette tip (i.e. the filament was brought to reddish color), the current was typically set to $\sim 1.2 \mathrm{~A}$ for filaments shaped as shown in Fig. $3 a$. The pressure polishing set-up was enclosed in a box, to protect 
the filament from air currents, that could strongly affect the filament temperature as well, and the entire set-up from dust. The optical field containing the filament and the pipette was viewed on an LCD monitor connected to a contrast-intensified CCD camera (VX 44, Till Photonics, Gräfelfing, Germany), that replaced the objective turret of a bright-field stereomicroscope (YS2-T, Nikon). The video signal was also digitized on-line (by Pinnacle Studio MovieBox DV, Avid, Burlington, MA, USA) and stored on a computer, to have a record of the pipette shaping process.
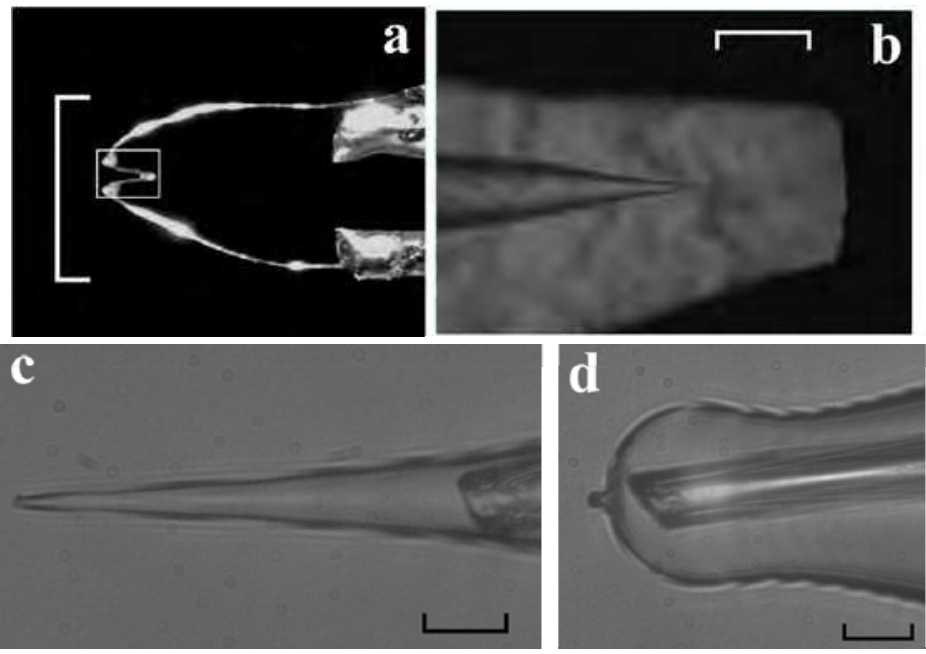

Fig. 3. Filament shape, pipette alignment, and controlled intracellular perfusion. $a$, the glasscoated platinum filament tin soldered to the holder; scale bar is $5 \mathrm{~mm}$. The "omega" shaped region of the filament within the white box is enlarged in $b$, where it is also shown a pipette before pressure polishing, correctly aligned with the filament; scale bar: $100 \mu \mathrm{m} . c$, a pulled quartz tube is positioned inside the lumen of a conventional pipette as close as possible to its tip; $d$, the same tube is inserted in a pressure polished pipette. Scale bar is $20 \mu \mathrm{m}$ in $c$ and $d$.

\section{Results and discussion}

\subsection{OS endogenous conductances and peptide characterization}

The vertebrate OS possesses just two endogenous conductances: the main one is the light sensitive (or cGMP) channel, the other one is the $\mathrm{Na}^{+}: \mathrm{Ca}^{2+}, \mathrm{K}^{+}$exchanger (reviewed in Rispoli, 1998). If the OS is illuminated, the light sensitive channels close, while the exchanger can be blocked if just one of the ion species transported by it (i.e. $\mathrm{Na}^{+}, \mathrm{Ca}^{2+}$ or $\mathrm{K}^{+}$) is removed from both sides of the membrane (Vedovato \& Rispoli, 2007b). To simplify the interpretation of the experiments, patch pipettes were filled with the same perfusion solution (that typically contained $130 \mathrm{mM}$ of $\mathrm{KCl}$ or $130 \mathrm{mM}$ of $\mathrm{NaCl}$ ) to ensure the current through the exogenous peptide pore was only driven by the holding potential ( $V_{h}$, usually set to $-20 \mathrm{mV}$ ). To preserve the membrane integrity during long recordings, it was necessary to include a physiological concentration of $\mathrm{Ca}^{2+}(1 \mathrm{mM})$ to the external solution (Vedovato \& Rispoli, 2007a). Therefore, $1 \mathrm{mM} \mathrm{Ca}{ }^{2+}$ was added to the intracellular solution as well, to 
ensure that the current was still entirely driven by $V_{h}$. Under these ionic conditions and under room lights (that will close all the light-regulated channels), the OS membrane resistance $\left(R_{m}\right)$ was usually larger than $1 \mathrm{G} \Omega$ in the absence of the peptide, exhibiting a linear (ohmic) current-to-voltage characteristic (Fig. 4).
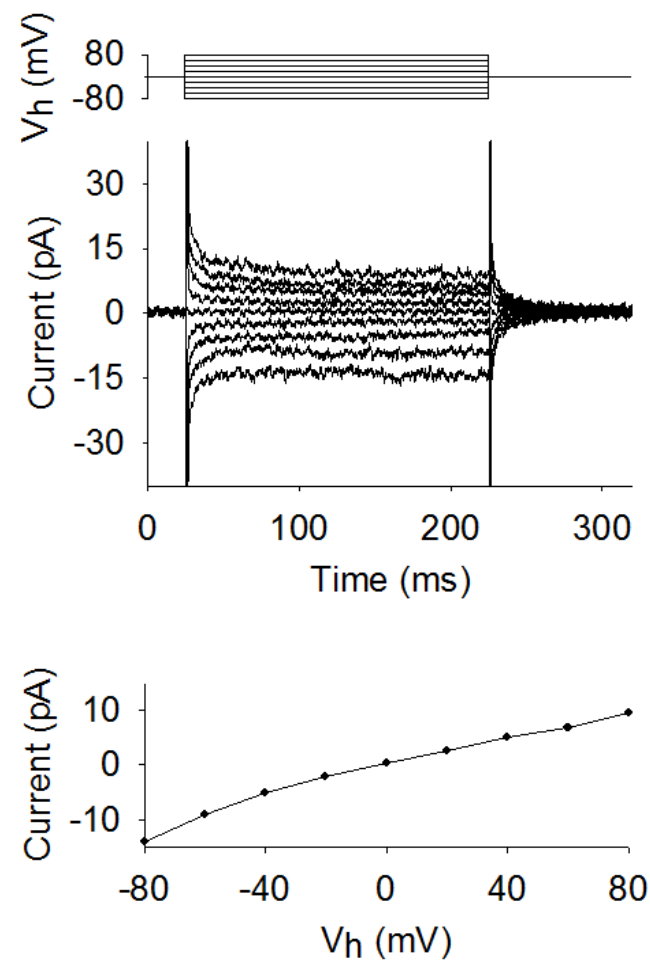

Fig. 4. Electrical properties of OS. Central panel: average whole-cell current recorded from a representative OS under room lights (pipette and external solution: $130 \mathrm{mM} \mathrm{K}+1 \mathrm{mM} \mathrm{Ca}^{2+}$ ), subjected to $5 \mathrm{~s}$ voltage steps from $-80 \mathrm{mV}$ to $+80 \mathrm{mV}$ in $10 \mathrm{mV}$ increments (top panel) starting from $V_{h}=0 \mathrm{mV}$ and repeated 10 times; lower panel, the average current recorded for each voltage step shown in the central panel is plotted against the voltage step (the resulting current-to-voltage characteristic is linear, giving $R_{m} \sim 8 \mathrm{G} \Omega$ ).

The high signal to noise ratio, given by the large value of $R_{m}$, allowed the detection of current signals down to the single channel level. The dynamics of the pore formation was tested by means of the following protocol (shown in Fig. $5 a, 6 b, 7 a, 8 a, 9 a$ and $c$ ). With the isolated OS continuously held to $V_{h}, R_{m}$ was measured before peptide perfusion by means of a brief $-10 \mathrm{mV}$ step (indicated with an asterisk in all figures); the peptide was then quickly applied (in about $\sim 50 \mathrm{~ms}$ ) using the fast perfusion system. Once the current had stabilized, the OS was finally returned to the control solution (without the peptide) to assess the possible recovery of the current, and $R_{m}$ was again measured. In control solution, repetitive $10 \mathrm{mV}$ pulses were routinely applied to check that $R_{a}$ was unchanged, otherwise the cell was discarded. 
In general, the waveform of the current induced by a peptide application and withdrawal can be described quantitatively by the following five kinetics parameters:

1. The activation delay $\left(D_{a}\right)$, defined as the time lag between peptide application and the time in which the current deviates from its baseline (following peptide application), more than three times the noise average fluctuation (indicated by the arrows in Fig. $7 \mathrm{c}$ and $e, 8 b$, and $9 b$ );

2. The activation time constant $\left(\tau_{a}\right)$, defined as the time constant of the single exponential fit to current activation (Fig. $7 a$ and $b$, black traces);

3. The current amplitude at steady-state $\left(I_{\max }\right)$;

4. The deactivation delay $\left(D_{d}\right)$, defined as the time lag between peptide removal and the time in which the current deviates from $I_{\max }$ more than three times the noise average fluctuation;

5. The deactivation time constant $\left(\tau_{d}\right)$ defined as the time constant of the single exponential fit to current deactivation (Fig. $7 a$ and $b$, black traces).

To avoid errors produced by the noise, the above parameters were measured on the lowpass filtered or on the smoothed traces (see Methods).

\subsection{Comparison between CM15 and F50/5 permeabilization properties}

Application of CM15 at concentrations $\leq 1 \mu \mathrm{M}$ gave no detectable macroscopic currents nor single channel events, but currents were routinely obtained at concentrations $\geq 2.5 \mu \mathrm{M}$ (Fig. 5, $6 a, 7 a, c$, and $d)$. Occasionally, at early times of peptide application at low concentration, current waveform resembled (barely) single channel events (the clearest recording ever
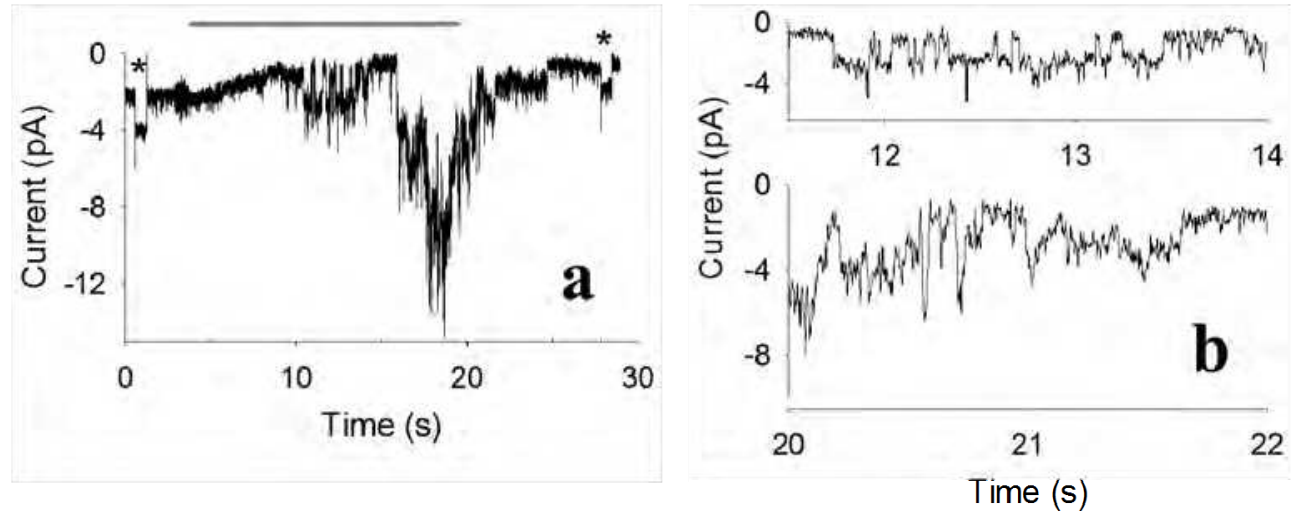

Fig. 5. Membrane permeabilization induced by CM15 at early times of recording at low concentrations. $a$, application for $16 \mathrm{~s}$ (grey thick line) and withdrawal of CM15 at concentration of $2.5 \mu \mathrm{M}$ on an OS recorded in whole-cell configuration. The membrane resistance was checked before and after peptide application by means of $-10 \mathrm{mV}$ pulses, indicated by the asterisks; holding potential was $-20 \mathrm{mV}$ throughout the recording. $b$, enlargements of the recording of $a 6.6 \mathrm{~s}$ after the perfusion onset (upper panel) and just after peptide removal from external solution (lower panel). To identify the temporal location of the two enlargements, timing of panels in $b$ follows the one of panel $a$. 
obtained is shown in Fig. 5). These events were followed by a noisy macroscopic current, that was expected to flow through several pores, which number was progressively increasing up to a steady-state number, as the peptide was continuously applied. It can be argued that the mechanism of pore formation by CM15 occurs according to a barrel and stave model: this requires that a certain number of monomers binds together once in the plasma membrane to form an ion conductive pore (Fig. 1). If the number of peptide
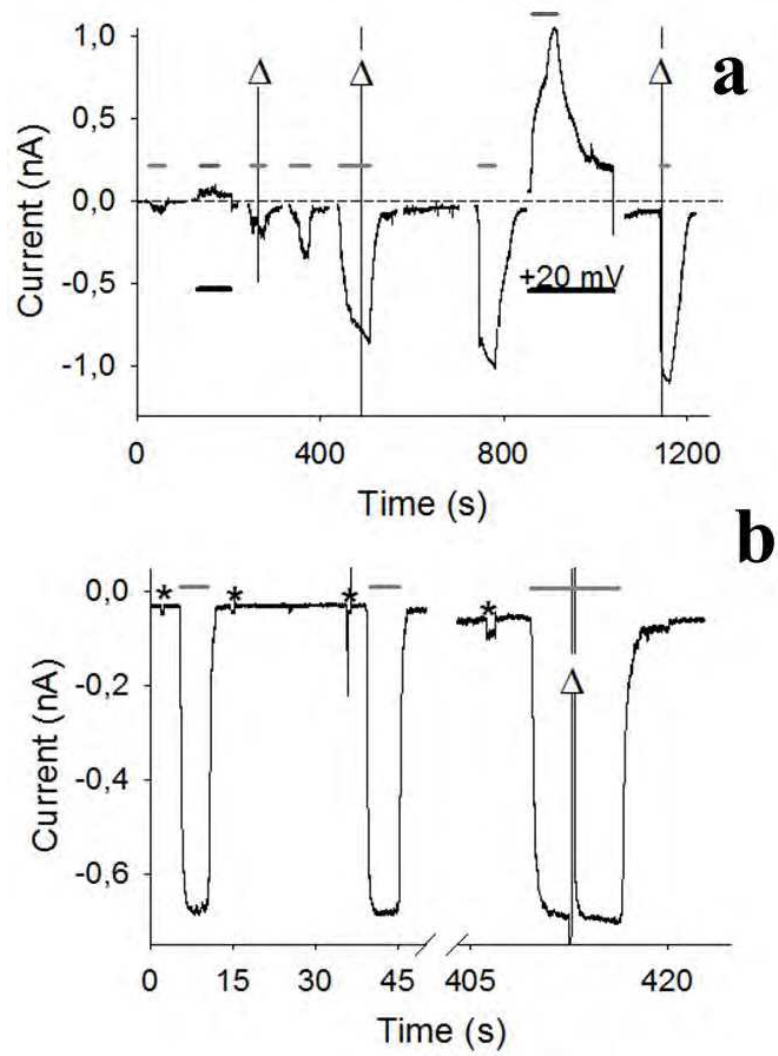

Fig. 6. Comparison between the currents elicited by repetitive applications of CM15 and F50/5. $a$, repetitive applications of CM15 at concentration of $5 \mu \mathrm{M}$ (thick grey lines); $V_{h}$ was $20 \mathrm{mV}$ but at the thick black lines, where it was $+20 \mathrm{mV}$; dotted line indicates the zero current at the beginning of recording (i.e. before any peptide application). $b$, repetitive applications of F50/5 at concentration of $1 \mu \mathrm{M}$ at $-20 \mathrm{mV}$. In both panels, the clipped vertical lines, indicated by the symbol $\Delta$, are actually the response to quick voltage ramps (see text) used to construct the current-to-voltage relationships (shown in Fig. $7 d$ ); the membrane resistance was checked before and after peptide application by means of $-10 \mathrm{mV}$ pulses, indicated by the asterisks; $V_{h}$ was $-20 \mathrm{mV}$ throughout the recording. The blanks in the recordings in control solution in $a$ and $b$ omit the repetitive voltage pulses used to measure $R_{m}, C_{m}$ and $R_{a}$ and/or the response to voltage ramps (a representative one is shown in Fig. $7 d$, thick black trace). 
monomers inserted in the membrane is small, as it occurs at early times of peptide application at low concentration, the pores are formed and disaggregated frequently, producing single channel events. However, besides the rarity of the occurrence of these events at early time of the recordings, they were never detected just after peptide removal, as instead expected, since the number of peptide monomers inserted in the membrane should return to be small again. At difference with CM15, low concentrations of F50/5 (and of their analogs reported in Table 1) gave clear and sustained single channel events (Fig. 8c; Vedovato \& Rispoli, 2007a). Incidentally, these channel events were produced by F50/5 at concentrations as low as $250 \mathrm{nM}$, showing a much larger efficiency in pore formation in eukaryotic cell membrane in respect to CM15.

The CM15 application at concentration of $5 \mu \mathrm{M}$ gave consistently macroscopic currents (Fig. $6 a$ ) that developed exponentially to a relatively stable level (Fig. 7a). This level was not however maintained if the peptide application was lengthen, but current kept slowly increasing throughout the peptide application (Fig. $6 a$ and $7 a$ ), at difference with sustained F50/5 perfusion (Fig. $7 b$ ), that produced very stable current. Moreover, repetitive CM15 applications produced currents of increasingly amplitude (Fig. 6a), but no such increase was ever observed with F50/5 (Fig. 6b). This again excludes that CM15 permeabilizes the plasma membrane according to a barrel and stave mechanism, since during continuous peptide application at high concentration, membrane peptides are expected to equilibrate with the ones externally perfused, giving a stable macroscopic current, as in the case of F50/5. Moreover, the current did not return to the zero level following peptide removal (Fig. $6 a$ and $7 a)$, but it recovered to a plateau level, where $R_{m}$ was consequently smaller in respect to the one measured before the peptide application. The CM15 concentration was larger, and/or more and more applications were performed (i.e. the larger was the current induced by CM15), the larger was the plateau amplitude and the smaller was the $R_{m}$ (measured during the plateau phase). This is again in contrast to F50/5, where current and $R_{m}$ fully recovered (Fig. $6 b$ and $7 b$ ) following peptide removal. In these experiments, the F50/5 and CM15 concentrations were selected to give currents smaller than $1 \mathrm{nA}$, since there is a voltage error induced by $R_{a}$ (that was typically $\sim 10 \mathrm{M} \Omega$ in the recordings considered in this chapter) that can be as high as $10 \mathrm{mV}$ at $1 \mathrm{nA}$ of current.

The kinetics parameters of current activation and deactivation defined in paragraph 3.1 can be measured from the fittings and the interpolations to the recordings as illustrated in Fig. $7 a, b, c$ and $e$. However, these parameters cannot be unambiguously estimated in the case of CM15, since they depend by the current amplitude. For instance, from the first exposure to the last one of Fig. $6 a, D_{a}$ progressively decreased from $2.6 \mathrm{~s}$ to $0.5 \mathrm{~s}$ and $\tau_{d}$ increased from 3.4 to $26.1 \mathrm{~s}$, as the current increased from $50 \mathrm{pA}$ to about $1 \mathrm{nA}$. To obtain a reproducible value of the kinetics parameters of the CM15-induced current, in order to compare them with the ones obtained with F50/5, CM15 recordings were selected to approximately give current amplitudes comparable to the ones induced by $1 \mu \mathrm{M}$ F50/5, irrespective of the CM15 concentration and/or the recording time. A representative example of one of these recordings is shown in Fig. $7 a$ (thick grey trace), that is compared to the much faster kinetics of F50/5 recordings (one example is in Fig. $7 b$, thick grey trace). This strong difference of permeabilization kinetics is better evidenced numerically by the 32-fold larger value of $\tau_{a}$ and $\tau_{d}$ of the CM15 recordings in respect to the F50/5 ones (Table 2), obtained by the monoexponential fittings to the activation and deactivation phases of both recordings 

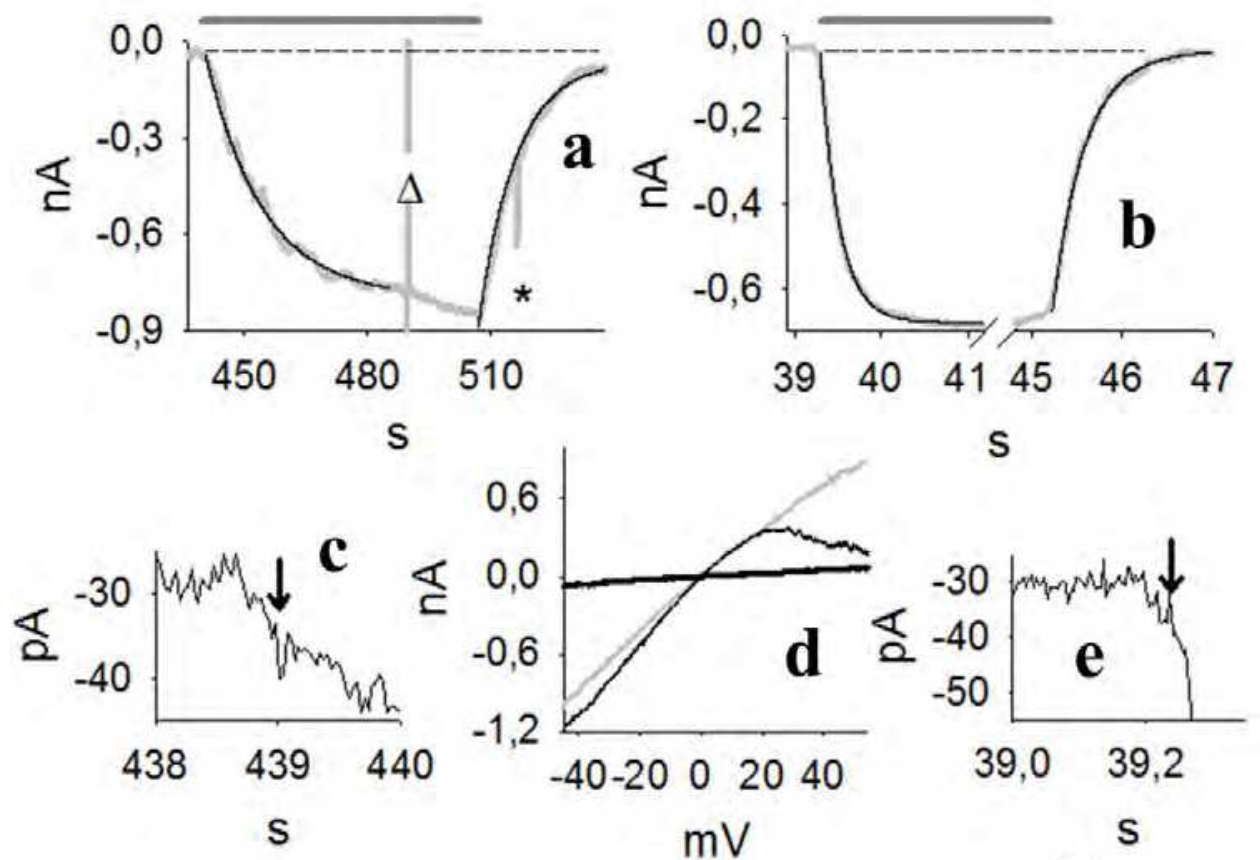

Fig. 7. Comparison of the kinetics parameters and the voltage dependence of the currents elicited by CM15 and F50/5. $a$, the fifth CM15 exposure of Fig. $6 a$ (the time scale follows the one of Fig. $6 a$ ) is enlarged and the activation and deactivation of the current are fitted with monoexponential curves, which time constants are $\tau_{a} \sim 14 \mathrm{~s}$ and $\tau_{d} \sim 9.1 \mathrm{~s}$, respectively. The first two seconds of this trace is further enlarged in $c$, starting with the time in which the peptide was applied (at $\sim 438 \mathrm{~s}$ from the beginning of recording of Fig. $6 a$ ), to show how $D_{a}$ was measured (indicated by the arrow, $D_{a} \sim 1 \mathrm{~s}$ ). $b$, the second F50/5 exposure of Fig. $6 b$ (the time scale follows the one of Fig. $6 b$ ) is enlarged and the activation and deactivation of the current are fitted with monoexponential curves which time constants are $\tau_{a} \sim 0.22 \mathrm{~s}$ and $\tau_{d}$ $\sim 0.36 \mathrm{~s}$, respectively. The first $350 \mathrm{~ms}$ of this trace is enlarged in $e$, starting with the time in which the peptide was applied (at $\sim 39$ s from the beginning of recording of Fig. $6 b$ ); $D_{a} \sim 0.21$ $\mathrm{s}$ (indicated by the arrow). $d$, voltage dependence of the current elicited by CM15 (thick grey trace) and by F50/5 (thin black trace) subtracted from the leakage, that was measured by applying the same voltage ramp in the absence of peptide (thick black trace). $D_{d}$ was measured for both CM15 and F50/5 with the same procedure shown in $c$ and $e$. Dotted lines in $a$ and $b$ indicate the zero current before peptide application.

(shown in Fig. $7 a$ and $b$, black traces). As expected, the average value of $D_{a}$ (Table 2) measured from the CM15 recordings on a fast time scale (indicated by the arrow in Fig. $7 c$ ) was larger than $D_{a}$ of F50/5 (Table 2; Fig. 7e). Moreover, $D_{d}$ was not measurable in the case of F50/5 (since the current started to decrease as soon as the solution change was completed), while it was significant in the case of CM15 (Table 2). The dramatically slower kinetics parameters of CM15 in respect to F50/5 ones, indicate that it takes a longer time to 
Enhanced Patch-Clamp Technique to Study Antimicrobial Peptides and Viroporins, Inserted in a Cell Plasma Membrane with Fully Inactivated Endogenous Conductances

\begin{tabular}{|c|c|c|c|}
\hline Parameter & CM15 (n=6) & F50/5 (n=10) & L-Glu(OMe) $)^{7,18,19}(\mathbf{n}=\mathbf{9})$ \\
\hline $\boldsymbol{D}_{a}(\boldsymbol{s})$ & $0.8 \pm 0.2$ & $0.21 \pm 0.03$ & $1.7 \pm 0.4$ \\
\hline$\tau_{a}(s)$ & $8.4 \pm 1.4$ & $0.26 \pm 0.02$ & $4.1 \pm 0.8$ \\
\hline $\boldsymbol{I}_{\max }(\boldsymbol{n} \boldsymbol{A})$ & $0.51 \pm 0.05$ & $0.70 \pm 0.03$ & $0.74 \pm 0.20$ \\
\hline $\boldsymbol{D}_{\boldsymbol{d}}(\boldsymbol{s})$ & $0.6 \pm 0.2$ & 0 & 0 \\
\hline$\tau_{d}(\boldsymbol{s})$ & $10 \pm 2$ & $0.31 \pm 0.02$ & $1.9 \pm 0.6$ \\
\hline
\end{tabular}

Table 2. Kinetics parameters of current elicited by CM15, F50/5, and L-Glu(OMe)7,18,19.

form pores with CM15 monomers than with F50/5 (i.e. $D_{a}$ and $\tau_{a}$ of the CM15 are larger than the ones of F50/5). Moreover, once formed, the CM15 pores are more difficult to be disaggregated upon ceasing the peptide supply at the external solution $\left(D_{d}\right.$ and $\tau_{d}$ of CM15 are again larger than the corresponding values measured for F50/5). In general, as $I_{\max }$ and the plateau amplitude following peptide removal progressively increased with repetitive CM15 applications, $D_{a}$ and $\tau_{a}$ progressively decreased while $D_{d}$ and $\tau_{d}$ progressively increased. It is conceivable that the CM15 monomers build up in several regions of the OS membrane to a concentration not enough large to give rise to conductive pores: these peptides may then contribute in forming new pores once the CM15 is applied again extracellularly, giving rise to the observed acceleration of activation kinetics of the current (i.e. decreasing $D_{a}$ and $\tau_{a}$ ). As expected, the resulting progressive build up of the number of conductive channels upon repeating the CM15 applications (that produced the progressive increase of $I_{\max }$ ), would slow down more and more the deactivation kinetics (i.e. increasing $D_{d}$ and $\tau_{d}$ ), since larger the number of channels (that are also more stable than the ones produced by F50/5), longer it takes to disaggregate them when ceasing the CM15 supply from the external solution. Collectively, all data presented so far exclude a barrel and stave model of pore formation of CM15, while they strongly support this model of permeation in the case of the F50/5. Moreover, the cell integrity and the substantial recovery of current, observed for CM15 applications and withdrawal at concentrations as high as $10 \mu \mathrm{M}$ (data not shown), exclude the carpet mechanism of membrane permeabilization at concentrations smaller than $10 \mu \mathrm{M}$, because micellation would produce the irreversible disruption of the membrane and cell lyses. It is however conceivable that, at high concentrations, CM15 could irreversibly permeabilize the membrane, by producing micellation according to the mechanism described in Fig. $1 f$. It therefore can be concluded that CM15 permeabilizes the membrane according to a toroidal model of pore formation. This view is also supported by the voltage-independency of CM15 membrane permeabilization, in contrast to F50/5, that instead inserts in the OS membrane at negative voltages (Vedovato et al., 2007; Vedovato \& Rispoli, 2007a; Fig. 7d). Indeed, CM15 application at $+20 \mathrm{mV}$ or $-20 \mathrm{mV}$ produced currents with similar $I_{\max }$ (and $D_{a}, D_{d}, \tau_{a}, \tau_{d}$ as well; Fig. $6 a$ ). However, the latter protocol is not suitable to assess the precise voltage dependency of the current, since the current progressively increases with repetitive applications of CM15 (note that the maximal current amplitude at $+20 \mathrm{mV}$ in Fig. $6 a$ is larger in respect to the one recorded at $-20 \mathrm{mV}$ ). To circumvent this problem, rapid voltage ramps (slope: $0.25 \mathrm{mV} / \mathrm{ms}$ ) were applied during CM15 perfusion at $V_{h}=-20 \mathrm{mV}$, once the current stabilized for a period at least as long as the ramp (400 ms). To avoid the loss of voltage control due to $R_{a}$ at extreme voltages (-60 and $+40 \mathrm{mV}$, where current may became very large), cells were selected to have currents of about $100-200 \mathrm{pA}$ at $V_{h}=-20 \mathrm{mV}$. The response to the voltage ramp during CM15 perfusion 
was subtracted to the response to the same voltage ramp recorded in control conditions (i.e. in the absence of peptide; Fig. $7 d$, thick black trace) to obtain the current-to-voltage relationship corrected for the leakage (Fig. $7 d$, thick grey trace). Relationship was almost perfectly ohmic for physiological voltages, in all cells examined $(n=6)$, in contrast with the strong inward rectification of the current-to-voltage relationship (corrected for the leakage) produced by F50/5 (Fig. $7 d$, thin black trace, $n=16$ ), obtained with the same voltage protocol used for CM15. Therefore, it is required a particular orientation of the F50/5 monomers (attained with the voltage) to form a conductive channel, while the CM15 monomers permeabilize the membrane regardless their orientation. This again supports the barrel and stave model for F50/5 and the toroidal model for CM15.

It can be argued that the pore formation according to the toroidal model could be ascribed to the relative abundance of lysine and/or leucine in respect to other aminoacids present in the CM15 sequence. Alternatively, the CM15-induced permeabilization might be due to some aspecific effect produced by the interaction of one or more of its amino acids with some membrane protein/s. These possibilities were however ruled out because a random sequence of the CM15 amino acids, (as the scrambled CM15; Table 1), was not able to produce any permeabilization, even for repetitive applications at $10 \mu \mathrm{M}$ concentration (lasting up to $3 \mathrm{~min} ; n=3$ OS; data not shown). Therefore, it is concluded that CM15 must be lined up in a precise sequence to produce efficient membrane permeabilization.

\subsection{F50/5 monomer assembling mechanism}

The barrel and stave model of pore formation requires that a certain number of peptide monomers binds together to form a functioning pore. The hydrophilic glutammine residues at positions 7, 18 and 19 of F50/5 are supposed to face the pore lumen and form hydrogenbonded rings, therefore they are expected to play a key role in channel formation. To examine the role of these residues in the pore formation, the amino acids in position 18 and 19 , or all of three, were substituted with a glutamic acid, in which a methyl ester group was linked to the carboxyl function in the $\gamma$ position. Two synthetic analogs, [L-Glu(OMe $)^{18,19}$ ] and [L-Glu(OMe $\left.)^{7,18,19}\right]$, were examined by applying them to the OS with the same protocol used to study the F50/5. Surprisingly, $1 \mu \mathrm{M}$ concentration of both analogs produced a current as large that induced by F50/5, showing that these residue substitutions do not prevent pore formation. However, while all the kinetics parameters and the noise of current elicited by [L-Glu(OMe ${ }^{18,19}$ ] were undistinguishable by the ones of F50/5, $D_{a}$ and $\tau_{a}$ of current elicited by [L-Glu(OMe $)^{7,18,19}$ ] were $\sim 8$-fold and $\sim 16$-fold, respectively, larger than those of F50/5 (Table 2): therefore, the kinetics of pore formation was fairly impaired in the latter analog, but not in the former, in respect to F50/5. Moreover, as the current developed, there was a much larger noise increase in respect to F50/5 (and [L-Glu(OMe) ${ }^{18,19}$ ]), indicating that $\left[\mathrm{L}-\mathrm{Glu}(\mathrm{OMe})^{7,18,19}\right]$ may form fewer channels, but with a larger single channel conductance, than those generated by F50/5. The latter peptide applied at $250 \mathrm{nM}$ concentration on the OS produced single channel events of several amplitudes, being not a simple multiple of a fixed size. Analysis of traces displaying very few channels (as the one shown in Fig. $8 c$, upper panel) allowed to estimate the smallest average single channel size, that resulted of $\sim 50 \pm 8 \mathrm{pS}$ at $-20 \mathrm{mV}$ (3500 events averaged in 3 cells). As expected, the single channel events produced by [L-Glu $(\mathrm{OMe})^{7,18,19}$ ] at concentration of $\sim 250 \mathrm{nM}$, were much larger than the F50/5 ones. Many different event amplitudes were produced by [L- 
$\left.\mathrm{Glu}(\mathrm{OMe})^{7,18,19}\right]$, and some were so fast that they were cut by the patch-clamp amplifier, even when filtering as high as $2 \mathrm{KHz}$ (Fig. $8 c$, bottom panel, grey trace). Since the majority of the events were anyway much slower, in order to compare the single channel amplitude of $\left[\mathrm{L}-\mathrm{Glu}(\mathrm{OMe})^{7,18,19}\right]$ with the one of F50/5, these very fast events were usually cancelled out
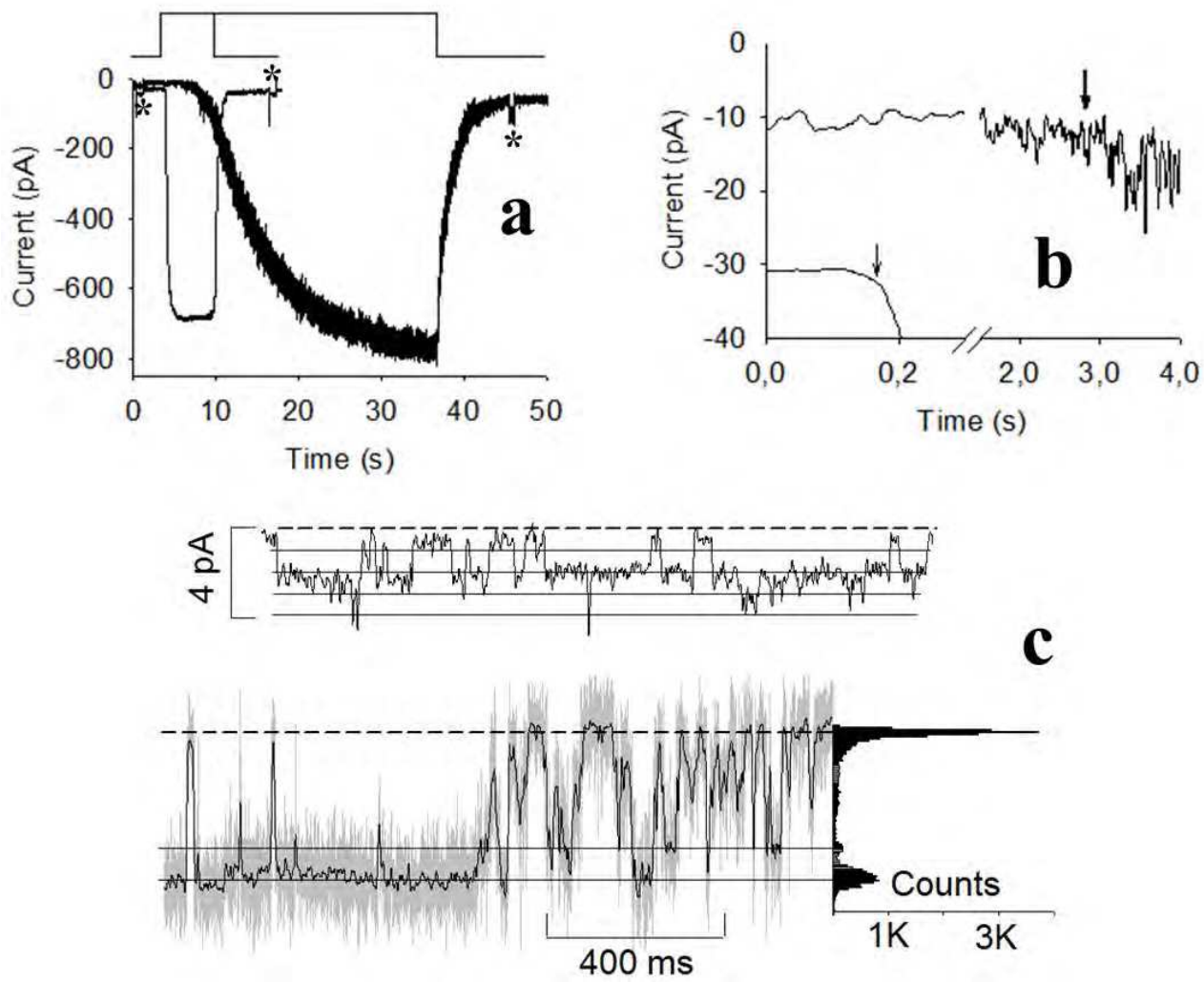

Fig. 8. Kinetics of OS membrane permeabilization induced by synthetic F50/5 and its [L$\mathrm{Glu}(\mathrm{OMe})^{7,18,19}$ ] analog. $a$, upper traces, timing of application and withdrawal of peptides at 1 $\mu \mathrm{M}$ concentration; lower trace, the voltage-clamp, whole-cell current recordings from one OS perfused with F50/5 (thin trace) and with [L-Glu $\left.(\mathrm{OMe})^{7,18,19}\right]$ (thicker trace). Asteriscs indicate the occurrence of the two $-10 \mathrm{mV}$ voltage pulses (superimposed to $\mathrm{V}_{\mathrm{h}}=-20 \mathrm{mV}$ ), used to measure $\mathrm{R}_{\mathrm{m}}$, that was about $1 \mathrm{G} \Omega$ before, and $20 \mathrm{~s}$ after, peptide application in both OS. $b$, the whole-cell current recordings of $a$ are smoothed to accurately measure the activation delay, indicated by the arrows, that is $0.17 \mathrm{~s}$ for F50/5 and $2.8 \mathrm{~s}$ for [L-Glu(OMe) ${ }^{7,18,19}$ ], computed from the solution change (that occurs at time 0 in this plot); the other kinetics parameters were, respectively: $\tau_{a}(0.21 \mathrm{~s}$ and $7.4 \mathrm{~s}), \tau_{d}(0.29 \mathrm{~s}$ and $1.6 \mathrm{~s})$, and $I_{\max }(700 \mathrm{pA}$ and $760 \mathrm{pA}$ at $\mathrm{V}_{\mathrm{h}}=-20 \mathrm{mV}$; see Table 2). c, upper panel, single channel events produced by F50/5; lower panel, left, channel activity produced by [L-Glu(OMe $)^{7,18,19}$ l low-pass filtered at $2 \mathrm{KHz}$ (grey trace) and at $100 \mathrm{~Hz}$ (superimposed black trace). Right, cumulative current amplitude distribution. Both recordings of $c$ have the same scales and $\mathrm{V}_{\mathrm{h}}=-20 \mathrm{mV}$; continuous and dotted lines indicate the most probable single channel amplitudes and $0 \mathrm{pA}$, respectively. 
upon low pass filtering the traces at $100 \mathrm{~Hz}$ (Fig. $8 c$, bottom panel, black trace). The distribution of current amplitudes (Fig. 8c, bottom panel, right) showed that the most probable amplitude was $310 \pm 30$ pS (820 events, n=3), but events of smaller sizes (as $260 \mathrm{pS}$ ) were recorded as well. For both peptides, current bursts occurred at very irregular intervals, making it impossible to systematically investigate interval duration, and measure key parameters as the open probability and the average open and closed time of the channel levels. The range of single channel amplitudes indicates that a channel is probably formed by several peptides assembled together, and various configurations of the peptide assembly are possible, depending upon the voltage, the peptide concentration and the duration of peptide application.

The slower kinetics of current activation formed by [L-Glu(OMe $)^{7,18,19}$ ] may simply reflect the smaller probability to assemble such large conductance channels. Consistently with this view, single channel events were recorded after $\sim 20 \mathrm{~s}$ of [L-Glu $\left.(\mathrm{OMe})^{7,18,19}\right]$ application to the OS $\left(\mathrm{V}_{\mathrm{h}}=-20 \mathrm{mV}\right)$, instead of $\sim 5 \mathrm{~s}$ as in the case of F50/5. Similarly to F50/5, the current fell to zero without any delay in respect to [L-Glu(OMe $\left.)^{7,18,19}\right]$ removal time, therefore this analog also does not stably integrate into the plasma membrane. Moreover, the current-tovoltage relationship of [L-Glu(OMe) $\left.{ }^{7,18,19}\right]$ was almost identical to the F50/5 one (shown in Fig. $7 d$, thin black trace).

Incidentally, the fact that the current elicited by F50/5 and by its analogs fell from several hundreds of $\mathrm{pA}$ to the single channel level following a 4 -fold reduction of peptide concentration, and that the peptide-elicited current fell to 0 within a few hundred of ms following peptide removal from the external solution (see, for example, Fig. $8 a$ and $c$ ), indicate that the pore formation and disaggregation are very fast and cooperative events.

For all peptide tested, the $D_{a}, I_{\max }, \tau_{a}$, and $\tau_{d}$ recorded in symmetric $\mathrm{Na}^{+}$were very similar to those reported in Table 2 (i.e., recorded in symmetric $\mathrm{K}^{+}$; data not shown).

All the above findings show that F50/5 and its analog [L-Glu(OMe)7,18,19], although exhibiting a very different kinetics of pore formation, retain the poor cation selectivity and the voltage dependency, that are typical features of peptaibols. However, they cannot conclusively indicate whether the ion conduction occurs through a pore formed with several peptide monomers assembled together, or it occurs along the inner portion of a single ahelices. The three dimensional structure of [L-Glu(OMe $\left.)^{7,18,19}\right]$ at a resolution of $0.95 \AA$, resolved from the electron density maps obtained by using the synchrotron radiation, consisted of two crystallographically independent bent a-helices, just long enough to span the membrane, but that cannot conduct ions through the hole produced by their helical arrangement (Crisma et al., 2007). Therefore, to explain the above electrophysiological results, and in particular the large current obtained at $1 \mu \mathrm{M}$ concentration of peptide and the occurrence of single channel events at low concentrations, it is concluded that the a-helices of F50/5 and its analogs assemble around a central pore that is able to conduct ions, according to the barrel and stave model (Fig. 1). The peptaibols constitute therefore the most ancestral form of ion channel, since all the voltage gated channels, the ligand gated channels and the gap junction found in all eukaryotic cells, are formed by several a-helices that pack together around a central ion conducting pore. 
Enhanced Patch-Clamp Technique to Study Antimicrobial Peptides and Viroporins,

\subsection{Viroporin permeabilization}

The experimental strategy described above to study antibiotic peptides, turned out to be very powerful to investigate also the molecular mechanism of membrane permeabilization induced by viroporins. One of the most dangerous viroporins for human health is the 97residues long poliovirus $2 \mathrm{~B}$, a non-structural protein required for effective viral replication, that has been implicated in cell membrane permeabilization during the late phases of infection. The experiments presented so far demonstrated that antimicrobial peptides comprising 15-20 residues are able to form membrane pores: it is then conceivable that a short domain of poliovirus $2 \mathrm{~B}$ sufficed to generate membrane permeabilization. Therefore, it was assessed the pore-forming properties of three peptides about 20 amino acid -long of an overlapping library that spanned the complete viroporin sequence. No significant changes of current level and of $R_{m}$ (Fig. $9 a$, grey trace) were induced by continuous perfusion of the 22-residues peptide at the beginning of poliovirus $2 \mathrm{~B}$ sequence ( 7 out of 7 OS; Table 1 , residues indicated in red) or at its end (5 out of 5 OS; Table 1, residues indicated in green) lasting up to $100 \mathrm{~s}$, for peptide concentrations up to $1 \mu \mathrm{M}$. Since the permeabilization induced by peptaibols was voltage-dependent (Fig. $7 d$ ), $V_{h}$ was changed in a range between -60 and $+60 \mathrm{mV}$ so to exclude that the lack of permeabilization was due to an inappropriate $V_{h}$ (Fig. $9 a$, grey traces). Concentrations as little as $33 \mathrm{nM}$ of the peptide spanning $2 \mathrm{~B}$ residues 35-55, (indicated in blue in Table 1), sufficed instead to significantly permeabilize the OS, and $100 \mathrm{nM}$ permeabilized the OS to a point that $R_{m}$ decreased by three order of magnitude and became comparable to $R_{a}$ (Fig. $9 a$, black trace and Fig. $9 c$; Table 3). This permeabilization process can be quantitatively described, besides by the $R_{m}$ change, by the parameters $D_{a}$ (indicated by the arrow in the inset of Fig. $9 b$ ) and $I_{\max }$ (see paragraph 3.1). However, $\tau_{d}$ and $D_{d}$ cannot be measured, because, at difference with peptaibols and CM15, no significant current recovery was observed upon removing this peptide from the external solution.

Moreover, current increased during the peptide application following a curve that cannot be interpolated with a single (or even a multiple) exponential: therefore, as far as the viroporin is concerned, $\tau_{a}$ symbolizes the $10-90 \%$ activation time, defined as the time interval in which the peptide induced current goes from $10 \%$ to $90 \%$ of the steady-state amplitude. The kinetics parameters of poliovirus 2B permeabilization on OS (Table 3) were measured at $V_{h}=-20 \mathrm{mV}$, so to compare them with the ones of the antibiotic peptides (Table 2). The current-to-voltage relationship with a voltage ramp from -60 to $+60 \mathrm{mV}$, measured once the current was stable, was linear and it was similar to the one predicted by the Ohm's law with a resistance equal to $R_{m}(22 \mathrm{M} \Omega$ in Fig. $9 d)$.

This is consistent with the view that the peptide must permeabilize the eukaryotic cell with high efficacy, independently by the cell state (as its membrane potential). Larger the peptide concentration, shorter was $D_{a}$, being as small as $0.5 \mathrm{~s}$ at $1 \mu \mathrm{M}$. However, at such high peptide concentration, $R_{m}$ became smaller than $R_{a}$, then $R_{m}$ could not be measured and the steadystate amplitude was meaningless (these two parameters were therefore not reported in Table 3). The large values of $D_{a}$ and $\tau_{a}$ indicate that this peptide must interact with the lipids for a long time, in respect to peptaibols and CM15, in order to permeabilize the membrane. This suggests that the membrane permeabilization occurs initially according to a toroidal model of pore formation; then, as more and more pores are formed, adjacent pores may restrict a micelle, that could detach and moves to the water phase, leaving a permanent hole behind, according to the carpet model of pore formation. 

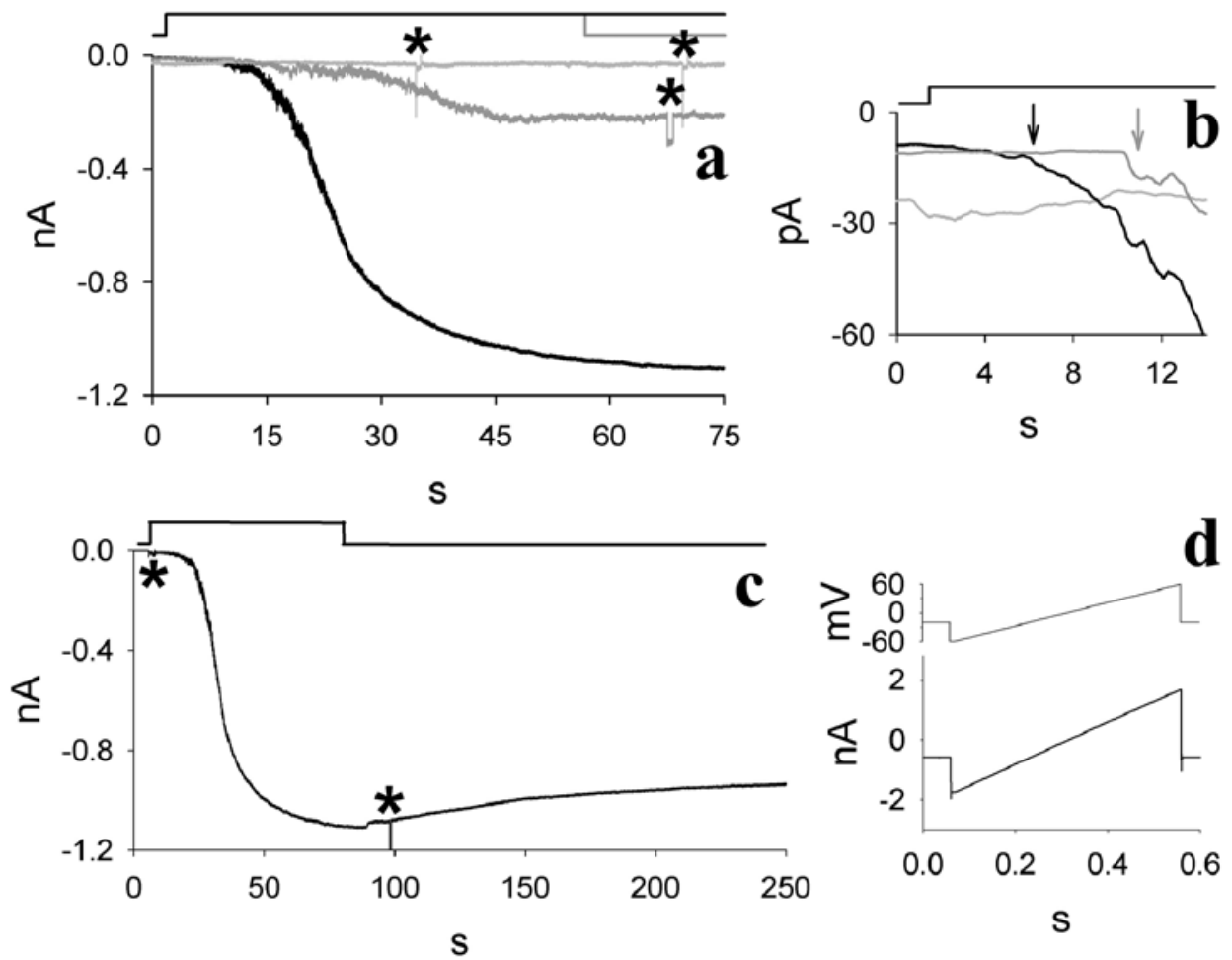

Fig. 9. Kinetics of OS membrane permeabilization induced by three domains of poliovirus 2B. a, current recorded during a $75 \mathrm{~s}$ application of: $1 \mu \mathrm{M}$ of a domain at the beginning (indicated in red in Table 1) and at the end (indicated in green) of the viroporin sequence (light grey trace), $33 \mathrm{nM}$ (grey trace), and $100 \mathrm{nM}$ (black trace) of the central domain (blue) of $2 \mathrm{~B}$ sequence $\left(V_{h}=-20 \mathrm{mV}\right.$ throughout the recording). The timing of peptide application is indicated by the black line above the recording but the $33 \mathrm{nM}$ peptide application, which is indicated in grey. $b$, same traces as $a$, but smoothed to accurately measure $D_{a}$ (indicated by the arrow) and $I_{\max }$, whose numerical values are reported in Table 2. $R_{m}$ before peptide application was measured from the current amplitude at $-20 \mathrm{mV}\left(-9.5 \mathrm{pA}, R_{m}=2.1 \mathrm{G} \Omega\right.$, black trace; $-27.0 \mathrm{pA}, R_{m}=0.8 \mathrm{G} \Omega$, grey trace; average: $1.8 \pm 0.9 \mathrm{G} \Omega, n=7)$. The $R_{m}$ following peptide application was measured once the current attained steady-state by using short $(0.74 \mathrm{~s})$ and small $(-10 \mathrm{mV})$ voltage pulses (indicated by the asterisks close to both traces) superimposed on $V_{h}$. At steady-state, $R_{m}$ (22 M $\Omega$ ) became comparable to $R_{a}(12 \mathrm{M} \Omega$ ) after the application of the central domain of poliovirus $2 \mathrm{~B}$ (in blue in Table 1), whereas it did not change significantly after perfusion of $1 \mu \mathrm{M}$ of either the other two domains (in red and in green in Table 1).c, current elicited by $100 \mathrm{nM}$ of the central domain shown in $a$ on a slower time scale. $d$, current (lower trace) elicited by a voltage ramp (top trace) from $-60 \mathrm{mV}$ to $60 \mathrm{mV}$ (slope: $0.244 \mathrm{mV} / \mathrm{ms}$; $V_{h}=-20 \mathrm{mV}$ ) applied once the current attained the steady-state during perfusion with 33 $\mathrm{nM}$ of the central domain. 
Enhanced Patch-Clamp Technique to Study Antimicrobial Peptides and Viroporins,

\begin{tabular}{|c|c|c|c|c|c|c|}
\hline Conc. $(\mathbf{n M})$ & $\boldsymbol{D}_{\boldsymbol{a}}(\boldsymbol{s})$ & $\mathbf{1 0 - 9 0 \%}(\boldsymbol{s})$ & $\boldsymbol{I}_{\max }(n \boldsymbol{A})$ & $\boldsymbol{R}_{m} \operatorname{pre}(G \Omega)$ & $\boldsymbol{R}_{m} \operatorname{post}(\mathbf{M} \boldsymbol{\Omega})$ & $\boldsymbol{R}_{\boldsymbol{a}}(\mathbf{M} \boldsymbol{\Omega})$ \\
\hline $33(n=3)$ & $9.9 \pm 2.6$ & $31.8 \pm 7.2$ & $0.22 \pm 0.08$ & $1.3 \pm 0.3$ & $110 \pm 40$ & $18 \pm 7$ \\
\hline $100(n=5)$ & $5.2 \pm 0.7$ & $25.0 \pm 1.7$ & $1.0 \pm 0.3$ & $2.0 \pm 0.8$ & $29 \pm 14$ & $17 \pm 8$ \\
\hline $1000(n=3)$ & $0.5 \pm 0.2$ & --- & --- & $1.2 \pm 0.5$ & --- & $18 \pm 8$ \\
\hline
\end{tabular}

Table 3. Kinetics parameters of current elicited by poliovirus $2 \mathrm{~B}$ at different concentrations.

\subsection{Pressure polishing procedure}

The permeabilizing domain of poliovirus $2 \mathrm{~B}$ has been applied on the external side of the OS. However, the ideal experiment would be delivering this peptide intracellularly, with a controlled timing, via the patch pipette by a tube inserted in its lumen, that should be placed as close as possible to the pipette tip. However, the long tapered shape of the pipette shank make it very difficult to perfuse efficiently the cell with this strategy (Fig. $3 c$ ). In the Methods is illustrated a further improvement of an existing technique widening the patch pipette shank, through the calibrated combination of heat and air pressure, that allowed to insert quartz or plastic tubes in the pipette lumen very close to its tip. Once the pipette was properly aligned with the filament (Fig. 3b), the box was closed and the air pressure and the filament heating were turned on and off for an appropriate time (to attain the desired pipette shape), with the three-way valve and the push-to-make switch, respectively. The shaping process of the pipette shank and of its tip was precisely followed using a calibration grating superimposed on the LCD monitor. The pipette shank geometry and its tip opening diameter could be finely controlled by adjusting: 1) the relative position of the pipette in respect to the filament, 2) the current intensity passing through the filament, 3) the duration of this current flow, 4) the pressure intensity, and 5) the duration of the pressure application while the current was flowing in the filament. In order to standardize the technique, the most efficient strategy found was to optimize the parameters 1), 2), and 4) and to keep them fixed throughout the pressure polishing process, while the third and the fifth parameters were left to be adjusted each time in order to obtain the desired shank profile and tip opening diameter. Long pressure applications (while the current was flowing in the filament), were used to obtain very enlarged shanks. If the pipette opening resulted too large for a given pressure duration, then its tip was heated again in the absence of pressure until the desired size was achieved; if it was instead too small, then that pressure duration was applied to pipettes pulled with larger tips. Therefore, by carefully regulating the duration of pressure and heating application, the pipette shank was widened as desired, while the tip opening diameter could be increased, decreased or left unchanged.

Pressure polished pipettes increased the rate of molecular diffusion between the pipette and the cell interior, allowing to perfuse viroporins or their domains and small proteins, making it possible the "real time modulation" of a multitude of cellular processes as well, as the signal transduction cascades. However, proteogenic molecules stick to the glass tip to the point to prevent seal formation, therefore it is important to add them to the pipette solution to a later time, i.e. after the seal was attained. In general, it is 
important to apply to the cytosol a particular molecule under test not at the beginning of the whole-cell recording, but to a desired later time. This goal can be realized by inserting in the pipette lumen pulled quartz tubes (or tubes fabricated with plastics that can be easily softened with a Bunsen flame, as polyethylene or polypropylene), filled with a solution containing the molecule under test. The latter can be ejected into the pipette solution with a pulse of pressure applied to the tube lumen. These tubes could be inserted very close to the tip of pipettes with a particularly enlarged shank (i.e. very close to the cell cytosol; Fig. 3d). Therefore, the molecules under test would be applied to the cell cytosol with a much shorter delay in respect to conventional pipettes (Fig. 3c), delay that can be up to $\sim 70 \mathrm{~s}$ for a small protein (having a diffusion coefficient of $\sim 10^{-6}$ $\mathrm{cm}^{2} \mathrm{~s}^{-1}$; Benedusi et al., 2011).

Another great advantage of the pressure polished pipettes is the strong reduction of $R_{a}$ since all the electrical resistance of these pipettes is given to the tip opening diameter and not also to the pipette shank. The pressure polished pipettes were thoughtfully tested on frog OS, because this is the most critical cell system among the ones tested. Indeed, to have reliably recordings from frog OS, it is necessary to use pipettes with a very small tip diameter (yielding therefore high $R_{a}$ if fabricated with conventional methods) to avoid to break the OS, because they are very fragile (Fig. $2 a$, inset) and they are often soiled with retina debris and vitreous humor. For pipettes shown in Fig. $3 d$ it resulted a 4 -fold reduction of $R_{a}$ in respect to the conventional ones (Benedusi et al., 2011).

Surprisingly, the chosen borosilicate glass (see Methods) was extremely good at attaining tight seals on an extremely wide variety of cells (being isolated or inserted in small tissue fragment or slice), or on giant unilamellar vesicles of many different lipid composition, providing that the pipettes and the pressure polishing set-up were maintained dirt-free, the pipette was kept in the bath as little as possible (to avoid that cell debris soiled the tip while approaching the cell), and the membrane target was "pressure cleaned" by ejecting as fast as possible the pipette solution onto the cell. It was not therefore true, as commonly believed, that different types of glass work better on different cell types (Penner, 1995): when there was a failure at attaining a seal, it was because the patch pipette tip was soiled, and/or because the membrane target was contaminated with cell debris, connective tissue or other organic material, not because the glass type was inappropriate. The day-to-day variability in attaining the seal was therefore entirely due to the cell quality (soiled or too fragile to sustain the sealing process), not to some uncontrollable parameter in the pipette fabrication. Given the "sealing power" of the glass pipette mentioned above, the pressure polishing technique was optimized just for this glass type.

\section{Conclusion}

The controlled application and withdrawal of peptides on isolated photoreceptor rod outer segments, recorded with the whole-cell voltage-clamp technique, resulted a powerful method to investigate the dynamics of pore formation and disassembly of membrane-permeabilizing peptides (as antibiotic peptides and viroporins) under strict physiological conditions. Moreover, the patch pipettes fabricated with the pressure 
polished technique, and used as described above, allowed to reduce of at least 4-fold the access resistance, to efficiently incorporate exogenous molecules in the cytosol especially via pulled quartz or plastic perfusion tubes, and to seal virtually on any natural or artificial phospholipid bilayer. The main results presented in this chapter can be summarized as follows:

1. One $\mu \mathrm{M}$ of alamethicin $\mathrm{F} 50 / 5$ produced an inward rectifying current that activated exponentially with a time constant of $\sim 300 \mathrm{~ms}$ to a steady-state amplitude of $0.7 \mathrm{nA}$ within $\sim 200$ ms from peptide application; at low concentration the F50/5 produced single channel activity of most probable conductance of $\sim 50 \mathrm{pS}$. The hydrophilic Gln residues at positions 7, 18 and 19 are not a key factor for pore formation, but [L$\left.\mathrm{Glu}(\mathrm{OMe})^{7,18,19}\right]$ analog produced larger pores $(\sim 300 \mathrm{pS})$, with a lower probability of formation than F50/5. All these peptides do not stably integrate into the plasma membrane and they form pores according to the barrel and stave model with a highly cooperative mechanism.

2. The cecropin-melittin hybrid peptide CM15 produced voltage-independent permeabilization of OS; repetitive peptide applications at concentrations $>2 \mu \mathrm{M}$ caused the progressive increase of the steady-state current amplitude. No clear single-channel events were detected at low peptide concentrations, while at concentrations as high as $10 \mu \mathrm{M}$ the cell integrity was preserved and the permeabilization was substantially reversible. Collectively, these results indicate that CM15 inserts in the plasma membrane according to the toroidal mechanism of pore formation.

3. A peptide spanning residues $35-55$ of the poliovirus $2 B$ produced irreversible membrane permeabilization, probably according to the carpet model, producing voltage-independent current at concentrations as low as $33 \mathrm{nM}$.

All these simple peptides are therefore not only an ideal tool to develop new antimicrobial and antiviral drugs, but they are important to understand the biophysical properties of much more complex molecules as channels and transporter proteins. The large variability of their pore-forming properties make them a potential lead for the development of bioactive compounds.

\section{Acknowledgment}

Technical assistance was given by Andrea Margutti, while Anna Fasoli and Cristina Mantovani helped with analysis and preparation of the new experiments presented in this chapter. Financial support to G.R. included grants from the Ministero dell'Università e della Ricerca (MIUR), Roma (Italy; Project PRIN 2008), from the "Comitato dei sostenitori dell'Università di Ferrara" (Project FAR: Correnti ioniche nei peptidi antibiotici e virali e nelle cellule sensoriali e gangliari, Ferrara, Italy).

\section{References}

Aili D., \& Stevens MM. (2010) Bioresponsive peptide-inorganic hybrid nanomaterials. Chem Soc Rev., Vol. 39, No.9, (July 2010), pp.3358-3370, ISSN 0306-0012 
Andreu D., Ubach J., Boman A., Wahlin B., Wade D., Merrifield R.B., \& Boman H.G. (1992) Shortened cecropin A-melittin hybrids. Significant size reduction retains potent antibiotic activity. FEBS Lett., Vol.296, No.2, (January 1992), pp.190-194, ISSN 00145793

Benedusi M., Aquila M., Milani A., \& Rispoli G. (2011) A pressure polishing set-up to fabricate patch pipettes virtually sealing on any membrane, yielding low access resistance and efficient intracellular perfusion. Eur Biophys J., Vol.40, No.4 (November 2011), pp.1215-1223, ISSN 0175-7571

Bockmann RA., Hac A., Heimburg T., \& Grubmuller H. (2003) Effect of sodium chloride on a lipid bilayer. Biophys J., Vol.85, No.3, (September 2003), pp.1647-1655, ISSN 00063495

Brogden K.A. (2005) Antimicrobial peptides: pore formers or metabolic inhibitors in bacteria? Nat. Rev. Microbiol., Vol.3, No.3, (March 2005), pp. 238-250, ISSN $1740-$ 1526

Carrasco L. (1995). Modification of membrane permeability by animal viruses. Advan. Virus Res., Vol. 45, pp. 61-112, ISSN 0065-3527

Crisma M., Peggion C., Baldini C., Maclean EJ., Vedovato N., Rispoli G., \& Toniolo C. (2007) Crystal structure of a spin-labeled, channel-forming alamethicin analogue. Angew Chem Int Ed Engl., Vol. 46, No.12, (September 2011), pp.2047-2050, ISSN 1433-7851

Chen HM., Clayton AH., Wang W., \& Sawyer WH. (2001) Kinetics of membrane lysis by custom lytic peptides and peptide orientations in membrane. Eur J Biochem., Vol.268, No.6, (March 2001), pp. 1659-1669, ISSN 0014-2956

Gadsby DC. (2009) Ion channels versus ion pumps: the principal difference, in principle. Nat Rev Mol Cell Biol., Vol. 10, No.5, (April 2009), pp.344-352, ISSN 1471-0072

Gonzalez ME., \& Carrasco L. (2003) Viroporins. FEBS Lett., Vol. 552, No.1, (September 2003), pp.28-34, ISSN 0014-5793

Goodman MB., \& Lockery SR. (2000) Pressure polishing: a method for re-shaping patch pipettes during fire polishing. J Neurosci Methods., Vol. 100, No.1-2, (July 2000), pp.13-15, ISSN 0165-0270

Johnson BE., Brown AL., \& Goodman MB. (2008) Pressure-polishing pipettes for improved patch-clamp recording. J Vis Exp. doi: 10.3791/964.

Hille B. (2001) Ionic channels of excitable membranes. (Third edition), Sinauer Associates, Inc. Sunderland, MA (USA), ISBN 0-87893-321-2

Hoskin DW., \& Ramamoorthy A. (2008) Studies on anticancer activities of antimicrobial peptides. Biochim Biophys Acta., Vol. 1778, No. 2, (November 2007), pp.357-375, ISSN 0006-3002

Madan V., Sánchez-Martínez S., Vedovato N., Rispoli G., Carrasco L., \& Nieva JL. (2007) Plasma membrane-porating domain in poliovirus 2B protein. A short peptide mimics viroporin activity. J Mol Biol., Vol. 374, No.4, (December 2007), pp.951-964, ISSN 0022-2836

Milani A., Benedusi M., Aquila M., \& Rispoli G. (2009) Pore forming properties of cecropinmelittin hybrid peptide in a natural membrane. Molecules., Vol.14, No.12, (December 2009), pp.5179-5188, ISSN 1420-3049 
Noshiro D., Asami K., \& Futaki S. (2010) Metal-assisted channel stabilization: disposition of a single histidine on the N-terminus of alamethicin yields channels with extraordinarily long lifetimes. Biophys J., Vol. 98, No.9, (May 2010), pp.1801-1808, ISSN 0006-3495

Papo N., \& Shai Y.(2005) Host defense peptides as new weapons in cancer treatment. Cell Mol Life Sci., Vol.62, No.7-8, (April 2005), pp.784-790, ISSN 1420-682X

Peggion C., Coin I., \& Toniolo C. (2004) Total synthesis in solution of alamethicin F50/5 by an easily tunable segment condensation approach. Biopolymers., Vol.76, No.6, pp. 485-493, ISSN 0006-3525

Penner R. (1995) A pratical guide to patch clamping. In: Single-Channel Recording, Sakmann B., \& Neher E., pp. 3-30, Plenum Press, ISBN 978-0-306-44870-6, New York

Pusch M., \& Neher E. (1988) Rates of diffusional exchange between small cells and a measuring patch pipette. Pflugers Arch., Vol.411, No.2, (February 1988), pp.204-211, ISSN 0031-6768

Rispoli G., Sather W.A., \& Detwiler P.B. (1993) Visual transduction in dialyzed detached rod outer segments from lizard retina. Journal of Physiology., Vol.465, (June 1993), pp. 513-537, ISSN 0022-3751

Rispoli G., Navangione A., \& Vellani V. (1995) Transport of K+ by $\mathrm{Na}(+)-\mathrm{Ca} 2+$, K+ exchanger in isolated rods of lizard retina. Biophys J., Vol.69, No.1, (July 1995), pp.74-83, ISSN 0006-3495

Rispoli G. (1998) Calcium regulation of phototransduction in vertebrate rod outer segments. J Photochem Photobiol B., Vol. 44, No.1, (June 1998), pp. 1-20, ISSN 1011-1344

Saint N., Cadiou H., Bessin Y., \& Molle G. (2002) Antibacterial peptide pleurocidin forms ion channels in planar lipid bilayers. Biochim Biophys Acta., Vol.1564, No.2, (August 2002), pp.359-364, ISSN 0006-3002

Suchyna TM., Markin VS., \& Sachs F. (2009) Biophysics and structure of the patch and the gigaseal. Biophys J., Vol.97, No.3, (August 2009), pp. 738-747, ISSN 0006-3495

Toniolo C., Crisma M., Formaggio F., Peggion C., Epand R. F., \& Epand R. M. (2001) Lipopeptaibols, a novel family of membrane active, antimicrobial peptides. Cell. Mol. Life Sci., Vol. 58, No.9, (August 2001), pp.1179-1188, ISSN 1420-682X

Vedovato N., Baldini C., Toniolo C., \& Rispoli G. (2007) Pore-forming properties of alamethicin F50/5 inserted in a biological membrane. Chem Biodivers., Vol.4, No.6, (June 2007), pp.1338-1346, ISSN 1612-1872

Vedovato N., \& Rispoli G.(2007a) A novel technique to study pore-forming peptides in a natural membrane. Eur Biophys J., Vol.36, No.7, (September 2007), pp.771-778, ISSN 0175-7571

Vedovato N., \& Rispoli G. (2007b) Modulation of the reaction cycle of the $\mathrm{Na}+\mathrm{Ca}+, \mathrm{K}+$ exchanger. Eur Biophys J., Vol.36, No.7, (September 2007), pp.787-793, ISSN 01757571

Wallace DP., Tomich JM., Eppler JW., Iwamoto T., Grantham JJ., \& Sullivan LP. (2000) A synthetic channel-forming peptide induces $\mathrm{Cl}(-)$ secretion: modulation by $\mathrm{Ca}(2+)-$ dependent $\mathrm{K}(+)$ channels. Biochim Biophys Acta., Vol.1464, No.1, (March 2000), pp.69-82, ISSN 0006-3002 
Wilde AA. (2008) Channelopathies in children and adults. Pacing Clin Electrophysiol.Vol.31, No.1, (February 2008), pp.S41-45, ISSN 0147-8389 


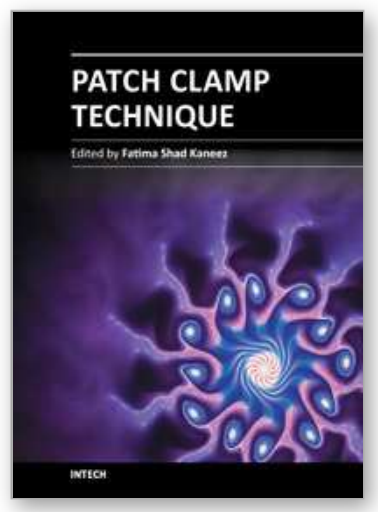

\author{
Patch Clamp Technique \\ Edited by Prof. Fatima Shad Kaneez
}

ISBN 978-953-51-0406-3

Hard cover, 356 pages

Publisher InTech

Published online 23, March, 2012

Published in print edition March, 2012

This book is a stimulating and interesting addition to the collected works on Patch clamp technique. Patch Clamping is an electrophysiological technique, which measures the electric current generated by a living cell, due to the movement of ions through the protein channels present in the cell membrane. The technique was developed by two German scientists, Erwin Neher and Bert Sakmann, who received the Nobel Prize in 1991 in Physiology for this innovative work. Patch clamp technique is used for measuring drug effect against a series of diseases and to find out the mechanism of diseases in animals and plants. It is also most useful in finding out the structure function activities of compounds and drugs, and most leading pharmaceutical companies used this technique for their drugs before bringing them for clinical trial. This book deals with the understanding of endogenous mechanisms of cells and their receptors as well as advantages of using this technique. It covers the basic principles and preparation types and also deals with the latest developments in the traditional patch clamp technique. Some chapters in this book take the technique to a next level of modulation and novel approach. This book will be of good value for students of physiology, neuroscience, cell biology and biophysics.

\title{
How to reference
}

In order to correctly reference this scholarly work, feel free to copy and paste the following:

Marco Aquila, Mascia Benedusi, Alberto Milani and Giorgio Rispoli (2012). Enhanced Patch-Clamp Technique to Study Antimicrobial Peptides and Viroporins, Inserted in a Cell Plasma Membrane with Fully Inactivated Endogenous Conductances, Patch Clamp Technique, Prof. Fatima Shad Kaneez (Ed.), ISBN: 978-953-510406-3, InTech, Available from: http://www.intechopen.com/books/patch-clamp-technique/enhanced-patchclamp-technique-to-study-antimicrobial-peptides-and-viroporins-inserted-in-a-cell-pla

\section{INTECH}

open science | open minds

\author{
InTech Europe \\ University Campus STeP Ri \\ Slavka Krautzeka 83/A \\ 51000 Rijeka, Croatia \\ Phone: +385 (51) 770447 \\ Fax: +385 (51) 686166 \\ www.intechopen.com
}

\author{
InTech China \\ Unit 405, Office Block, Hotel Equatorial Shanghai \\ No.65, Yan An Road (West), Shanghai, 200040, China \\ 中国上海市延安西路65号上海国际贵都大饭店办公楼 405 单元 \\ Phone: +86-21-62489820 \\ Fax: +86-21-62489821
}


(C) 2012 The Author(s). Licensee IntechOpen. This is an open access article distributed under the terms of the Creative Commons Attribution 3.0 License, which permits unrestricted use, distribution, and reproduction in any medium, provided the original work is properly cited. 